Research Article

\title{
Development of Compact Load Cell Using Multiwall Carbon Nanotube/Cotton Composites and Its Application to Human Health and Activity Monitoring
}

\author{
Md. Abdul Momin $\left(\mathbb{D},{ }^{1}\right.$ Mohammad Jellur Rahman $\mathbb{D}^{2},{ }^{2}$ and Tetsu Mieno $\mathbb{D}^{1,3}$ \\ ${ }^{1}$ Graduate School of Science \& Technology, Shizuoka University, Shizuoka 422-8529, Japan \\ ${ }^{2}$ Department of Physics, Bangladesh University of Engineering and Technology, Dhaka 1000, Bangladesh \\ ${ }^{3}$ Department of Physics, Shizuoka University, Shizuoka 422-8529, Japan \\ Correspondence should be addressed to Md. Abdul Momin; mamomin89bd@gmail.com
}

Received 16 February 2019; Accepted 14 March 2019; Published 30 April 2019

Academic Editor: Stefano Bellucci

Copyright (c) $2019 \mathrm{Md}$. Abdul Momin et al. This is an open access article distributed under the Creative Commons Attribution License, which permits unrestricted use, distribution, and reproduction in any medium, provided the original work is properly cited.

\begin{abstract}
Compact load cells have been developed using multiwall carbon nanotube/cotton (MWCNT/cotton) composites, whose performance has been optimized by varying the concentration of MWCNTs and the thickness of the composite. The sensitivity of the load cell, which is defined as the ratio of the change in the relative electric resistance to the change in applied pressure, is measured to be in the range of $180-0.20 \mathrm{kPa}^{-1}$ for applied pressures of $8.84 \mathrm{~Pa}-884 \mathrm{kPa}(F=1.0 \mathrm{mN}-100 \mathrm{~N})$. The load cells show a rapid response in situations with a frequently changing force, with response times $\tau_{1 / 2}$ of 4.5 and $5.0 \mathrm{~ms}$ for the application and release of load, respectively. The load cell demonstrates high reproducibility in tests involving more than 11,200 compression/relaxation cycles. It also has high reproducibility in different harsh environments and has a good electricconductance recovery property. The load cell is successfully used to monitor the time-varying center of gravity of a human foot, which can be applied to the diagnosis of sick and healthy people. The MWCNT/cotton load cells can be used as wearable and flexible devices for monitoring human health.
\end{abstract}

\section{Introduction}

Applications of carbon nanotubes (CNTs) have been extensively studied owing to their various outstanding properties such as high aspect ratio, large surface area, light weight, and high tensile strength [1-4]. Recently, CNT/polymer composites have been used in flexible, wearable, and stretchable devices [5-7]. The design of wearable sensors is a challenging and attractive discipline in modern technology. Flexible, stretchable, and lightweight pressure sensors have a diverse range of applications, such as health monitoring [8-10], performance monitoring during sports [11-13], artificial robotic skin $[14,15]$, and heartbeat monitoring [16]. However, electronic sensors and devices have been developed on rigid and fragile wafers. In the future, electronic sensors and devices are expected to be more integrated, versatile, stretchable, soft, and human-friendly.
Different types of pressure sensors have been developed, such as piezoelectric sensors $[17,18]$, capacitive sensors [19-21], piezoresistive pressure sensors [22-26], and transistor-type pressure sensors [27], and have been used for many purposes. Recently, a capacitive pressure sensor developed using polydimethylsiloxane (PDMS) has been reported to have a sensitivity of about $0.26 \mathrm{kPa}^{-1}$ in the lowpressure range of $0-0.33 \mathrm{kPa}$ and a sensitivity of $0.01 \mathrm{kPa}^{-1}$ in the high-pressure range of $0.33-250 \mathrm{kPa}$ [28]. The sensitivity of a pressure sensor is defined as the ratio of the change in relative resistance $\left(\Delta R / R_{0}\right)$ to the change in pressure $(\Delta p)$,

$$
S=\frac{\left(R_{L} / R_{0}-1\right)}{\Delta p},
$$

where $R_{\mathrm{L}}$ is the resistance under the load, $R_{0}$ is the load-free resistance, and $\Delta p$ is the change in applied pressure. Gong 
et al. [29] have developed pressure sensors using ultrathin $\mathrm{Au}$ nanowires that have a sensitivity of more than $1.14 \mathrm{kPa}^{-1}$ with a response time of less than $17 \mathrm{~ms}$, which can be used for monitoring human blood pressure and the detection of small vibrations. The desired properties for wearable pressure sensors include flexibility, repeatability, and low environmental impact. When sensors are worn, comfort is also important. Flexible and skin-mountable strain sensors have been developed using polyurethane acrylate and PDMS. These sensors have a rapid response, exhibit reproducibility for up to 10,000 cycles in on/off tests, and can be used as wearable human heartbeat detectors [26]. Conducting multiwall carbon nanotubes (MWCNTs) can be constructed into amalgamated structures to fabricate sensors [30]. Recently, strain sensors have been developed from cotton threads. These sensors have a short relaxation time and good durability and can be used to detect human blood pressure [31]. Pressure sensors using cotton and polydimethylsiloxane (CC/PDMS) with a sensitivity as high as $6.04 \mathrm{kPa}^{-1}$ have been developed to monitor sports performances [32]. However, only one sensor was used to monitor performances, and the sensors were rather large and bulky. Moreover, their toughness and range of operating conditions were not reported [32].

Recently, water-dispersible MWCNT derivatives have been developed, which have been used to coat cotton textiles with high stability [33]. This MWCNT-coated cotton material has controllable electric conductance. Using this material, we were able to develop new and potentially valuable compact load cells. These load cells have sensitivities of $180-0.20 \mathrm{kPa}^{-1}$ in the range of forces $F=1 \mathrm{mN}-100 \mathrm{~N}$ $(p=8.84 \mathrm{~Pa}-884 \mathrm{kPa})$, which are higher than those of the CC/PDMS pressure sensors [32]. These new load cells (in this study) have short activation and relaxation time constants of $\tau_{1 / 2} \simeq 4.5$ and $5.0 \mathrm{~ms}$, respectively (the definition of $\tau_{1 / 2}$ is $50 \%$ of the activation or relaxation time), and they are thin and compact. In this study, the reproducibility of the load cells in pressure measurements is investigated, and high reproducibility under different harsh ambient conditions is demonstrated, as well as high durability in tests involving more than 11,200 repeated compression/relaxation cycles. The responses of the cells at different temperatures and humidities are almost the same. The load cells show good reversibility and almost zero hysteresis. When the load cells are set in the sole of a shoe, they show clear responses to walking and jogging, making them promising for monitoring human health and real-time sports performances. The center of gravity of a human foot can be measured by using three load cells set in the sole of a shoe, which can be used to record the balance of sick and elderly people. As the load cells are tough and compact with high sensitivity, a short response time, and high reproducibility under many ambient conditions, they can be used in monitoring human health, sports performances, and other valuable applications.

\section{Experimental Setup and Methods}

2.1. Materials. Natural cotton fibers are used to fabricate the load cells. Pure cotton generally consists of soft and comfortable fibers. The density of cotton is in the range of $1.54-1.56 \mathrm{~g} / \mathrm{cm}^{3}$, and it contains about $91 \%$ cellulose, $7.9 \%$ water, and small amounts of other materials. MWCNTs (purity, 95-97.5\%; Flo Tube 9000, CNano Technology Ltd.) of $10-11 \mathrm{~nm}$ diameter and lengths of $<10 \mu \mathrm{m}, 5-8$ number of walls, and absorbent cotton fibers of about $10 \mu \mathrm{m}$ diameter (cotton wool, Hakujuji Co.) are used to form MWCNT/cotton composites, which are the filler materials of the load cells.

2.2. Preparation of MWCNT/Cotton Composites. Pristine MWCNTs are not dispersible in water because of the van der Waals attractive forces among them and because they do not have hydrophilic groups [34]. Therefore, MWCNTs are functionalized using citric-acid-assisted oxygen plasma, as a result of which they become dispersible in water [33, 35]. First, $30 \mathrm{mg}$ of MWCNTs is placed in $20 \mathrm{ml}$ of ethanol and dispersed by a supersonic homogenizer (Sonic VibraCell, VC130, Sonics and Materials Inc.) under an input power of $20 \mathrm{~W}$ for $1 \mathrm{~h}$, then dried under reduced pressure. Next, the MWCNTs are soaked in $5 \mathrm{ml}$ of $0.3 \mathrm{M}$ citric acid solution for $48 \mathrm{~h}$. Then, the wet sample is treated with a capacitively coupled RF oxygen plasma. About $30 \mathrm{mg}$ of the MWCNTs is set on a lower electrode in the plasma reactor and treated for $15 \mathrm{~min}$ at an RF power of $200 \mathrm{~W}$. An RF generator (RF-500, Tokyo Hy-Power Inc.) with a frequency of $f=13.56 \mathrm{MHz}$ is used to supply the power. The oxygen pressure during the plasma treatment is maintained at about $400 \mathrm{~Pa}$. A mass flow controller (SC-ED4-2M, HORIBA STEC Co.) is connected to the plasma chamber and the flow rate of oxygen is set at $5 \mathrm{ccm} / \mathrm{min}$. As a result of these treatments, the MWCNTs are functionalized and $\mathrm{COOH}$ groups as well as some $\mathrm{OH}$ groups attach on their surface $[33,36]$.

The functionalized MWCNTs (f-MWCNTs) are taken out from the chamber and washed several times with pure water to remove unreacted citric acid. The f-MWCNTs are placed in pure water and sonicated for $15 \mathrm{~min}$, after which they are thoroughly dispersed in water. This MWCNT ink is stored in glass bottles. Then, about $0.20 \mathrm{~g}$ of natural cotton aggregate is dipped into the MWCNT ink several times then dried at room temperature on a petri dish and MWCNT-coated cotton composite is obtained [37-40], as shown in Figures 1(a)-1(c). The electric conductance of the composites is measured using a digital multimeter (R6341A, Advantest Co.).

2.3. Production of MWCNT/Cotton Load Cells. Compact load cells have been developed using the MWCNT/cotton composites. The fabrication process of the load cell is shown in Figures 1(a)-1(e). A plastic housing case (outer diameter, $25.0 \mathrm{~mm}$; inner diameter, $12.0 \mathrm{~mm}$; outer height, $15.0 \mathrm{~mm}$; and inner height, $10.0 \mathrm{~mm}$ ) is used as the holder of the load cell as shown in Figure 2. Two nickel sheets (The Nilaco Corporation) of $0.030 \mathrm{~mm}$ thickness and $12 \mathrm{~mm}$ diameter are used as the two parallel electrodes of the load cell. Two thin copper wires of $0.30 \mathrm{~mm}$ diameter are connected to the electrodes. The diameter of the MWCNT/cotton composite is $12 \mathrm{~mm}$, and the cross section is $A_{0}=113.1 \mathrm{~mm}^{2}$. For this cell, the application of a force of $1 \mathrm{~N}$ corresponds to a pressure of $8.84 \mathrm{kPa}$. 

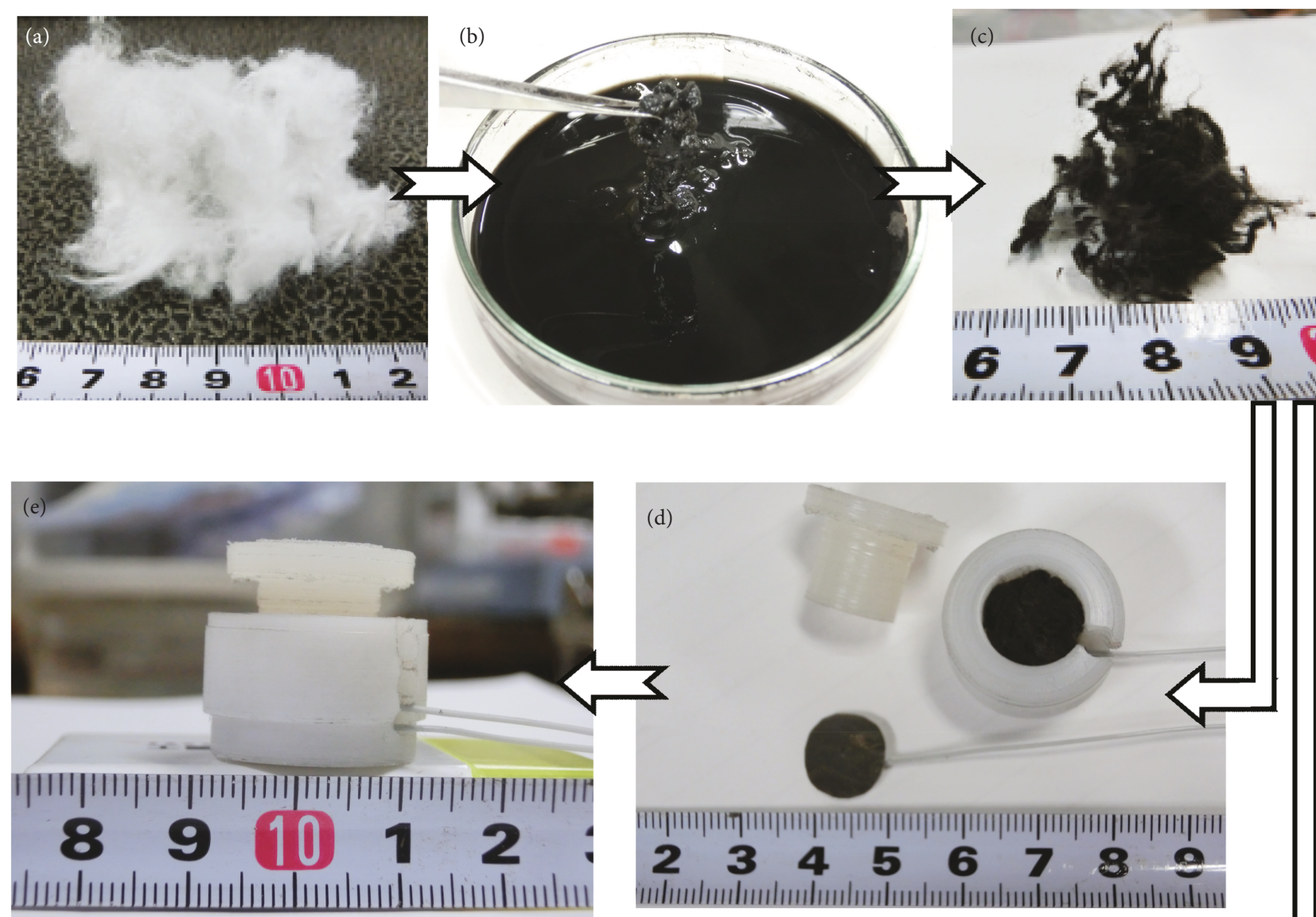

(d)

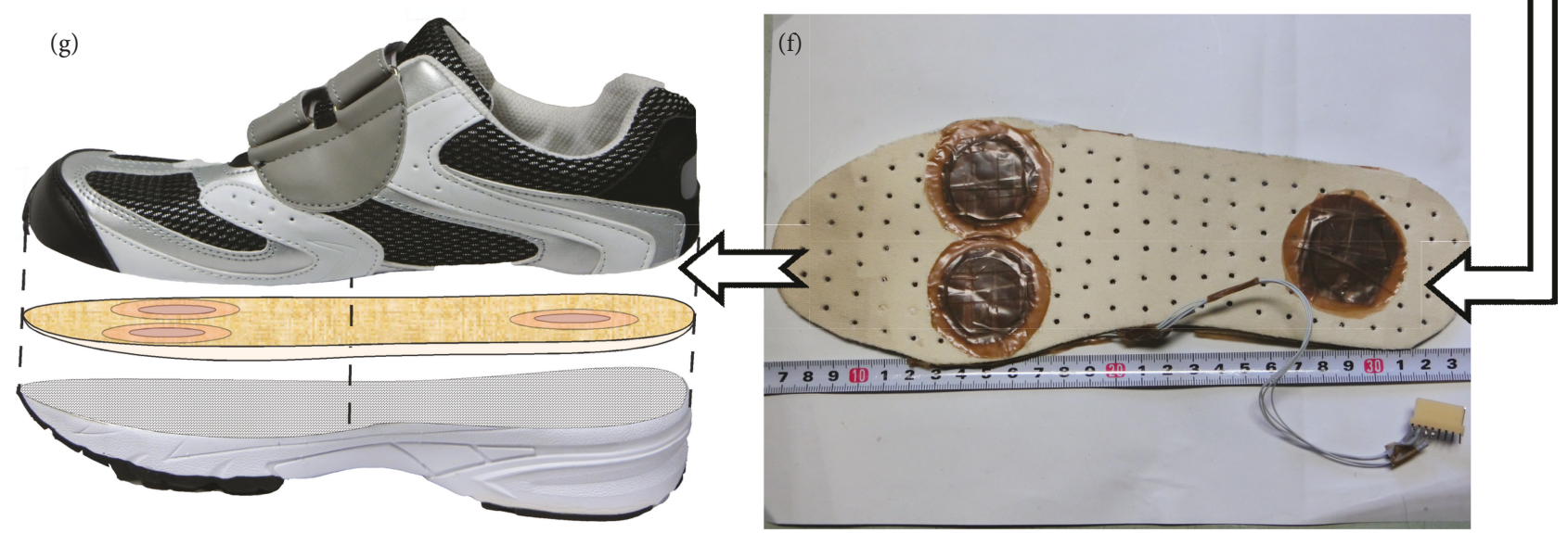

FIGURE 1: Fabrication process for the MWCNT/cotton load cells. (a) Raw cotton material after blending process. (b) The cotton aggregate is dipped in MWCNT ink. (c) Dried MWCNT/cotton composite sample. (d) The composite is set in a plastic housing to form a load cell. (e) Prepared load cell with copper wires. (f) These three cells are set in a soft plastic shoe sole with thin plastic tape used to fix them. (g) The insole based-load cells are placed inside a running shoe.

2.4. Production of Foot Pressure Sensors Using the Load Cells. To develop foot pressure sensors, three flat load cells are set in a soft plastic shoe sole (Jinjiang Lizeng Shoes Material Co.) length of $270 \mathrm{~mm}$. First, three holes of $15 \mathrm{~mm}$ diameter are made in the shoe sole, then load cells of $15 \mathrm{~mm}$ diameter, $4 \mathrm{~mm}$ thickness, and a surface area of $A_{0}=176.7 \mathrm{~mm}^{2}$ are placed in them. A schematic diagram of the foot pressure sensors is shown in Figure 3. A thin and flexible fluorinated plastic tape (NITOFLON, No. 903UL, Nitto Denko Co.) of $0.5 \mathrm{~mm}$ thickness is used to fix the load cells in the sole so that the MWCNT/cotton fibers cannot touch human body directly. A cross section of a sensor cell is shown in Figure 3(a). Finally, the plastic sole is set in a shoe, as shown in Figures $1(\mathrm{f})$ and $1(\mathrm{~g})$, to monitor human movement 


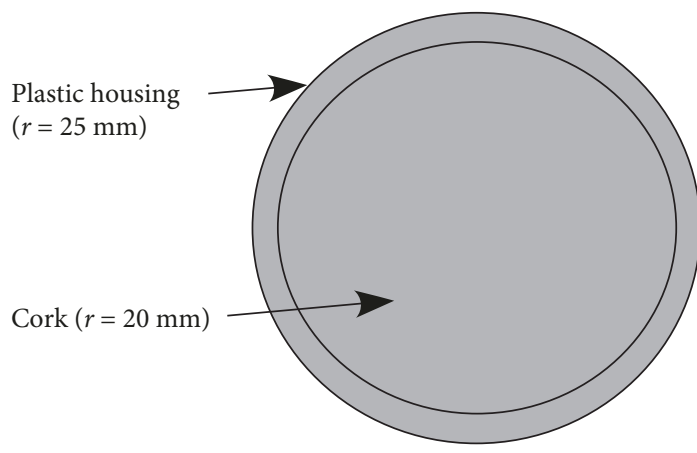

Top view

(a)

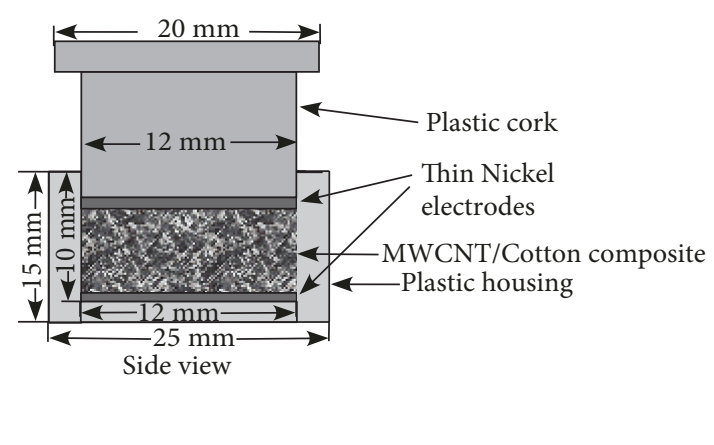

(b)

Figure 2: Schematic diagram of an MWCNT/cotton load cell. (a) Top view and (b) side view.

(a)

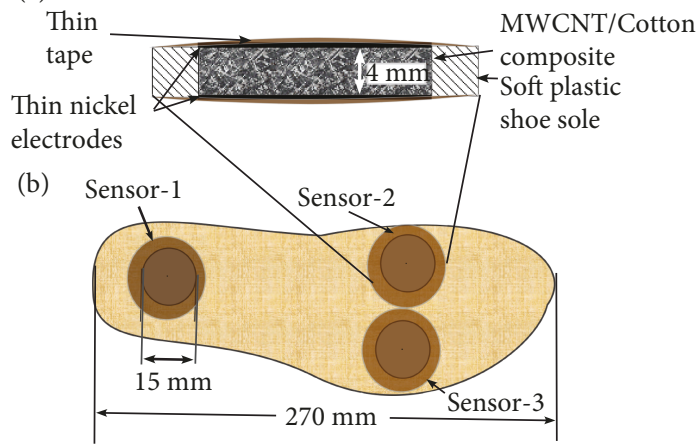

FIgURE 3: (a) Schematic of cross section of a load cell embedded in a soft plastic shoe sole. (b) Top view of foot pressure sensors embedded in the shoe sole.

(walking, jogging, etc.). The positions of the load cells are decided by referring to the three common supporting points of a foot of a human in the standing position which is shown in Figure 3(b).

2.5. Characterization of the Load Cells. Images of the MWCNT/cotton composites are obtained by scanning electron microscopy (SEM) (JSM-6510, JEOL Co.) with and without a force applied to the composites. The MWCNT/cotton composites are pressed with a force of about $10 \mathrm{~N}$ using a small metal vice.

Various mechanical tests are carried out to determine the sensitivity and time response of each load cell. To observe the pressure-sensing performance, a load test machine (1308, Aikoh Engineering Co.) is used to apply a force to the load cell. A data recorder (midi LOGGER, GL200A, Graphtec Co.) is used to record the electric conductance data. The circuit shown in Figure 4(a) is used to measure the conductance of the load cell. The data are recorded at 100,20, 10, and $2 \mathrm{~ms}$ intervals. A $9 \mathrm{~V}$ battery is used to supply dc power to the circuit. A resistor of $1.0 \mathrm{k} \Omega$ resistance is connected to the cell to record the circuit current. Two channels of the data recorder are used to measure the voltages $V_{1}$ and $V_{2}$. The resistance $R_{\mathrm{s}}$ and conductance $\sigma$ of the cell are evaluated using the following simple equations:

$$
\begin{aligned}
& R_{\mathrm{s}}=\frac{V_{1}}{V_{2}} \times R, \\
& \sigma=\frac{1}{R_{\mathrm{s}}}=\frac{V_{2}}{V_{1}} \times \frac{1}{R},
\end{aligned}
$$

where $R$ is $1.0 \mathrm{k} \Omega$. Different loads are used to measure the change in the conductance of the load cell. A speedcontrolled motor (MSM425, Oriental Motor Co.) and a metal weight are used in endurance tests repeatedly to apply a force to the load cell. The load cell is subjected to temperatures of -20 to $80^{\circ} \mathrm{C}$ and different humidity conditions. During the endurance tests, the loading and unloading of a force of $2.0 \mathrm{~N}$ are repeated.

To demonstrate the potential applications of the flexible load cells, they are placed inside a running shoe. The assembly of the load cells mounted in the sole of the shoe, and the cross section of a single cell are shown in Figure 3. The sole is set in a shoe (Zephyr Workgear Co.) for the foot pressure test. A circuit diagram for the foot pressure test is shown in Figure 4(b). The three cells are connected with a $9 \mathrm{~V}$ battery and three resistors of $1.0 \mathrm{k} \Omega$ resistance. Six channels of the data recorder are used to record the output voltages of the three load cells at a sampling rate of 10 or 100 samples/s. The movements of a wearer under walking and jogging conditions are monitored using the load cells. The time variation of the center of gravity of a human foot is measured when the wearer is standing on one foot. The center of gravity is measured under two conditions with the eyes of the wearer open and closed. This test can be used to diagnose sick people and the progress of rehabilitation.

\section{Results and Discussion}

3.1. Morphology of MWCNT/Cotton Composites. A highresolution SEM image (Figure 5(a)) of an MWCNT/cotton composite under the force-free condition shows $10 \mu \mathrm{m}$ diameter crooked cotton fibers. The composite is pressed using a small metal vice under a force of about $10 \mathrm{~N}$ and 


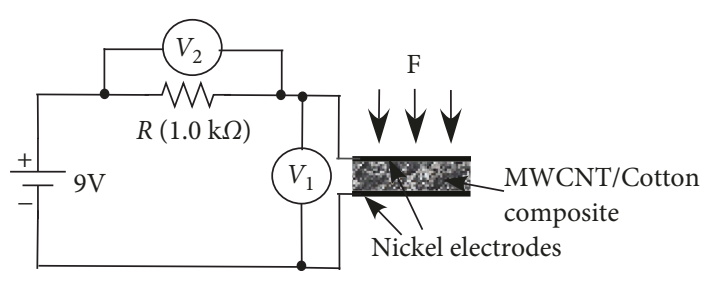

(a)

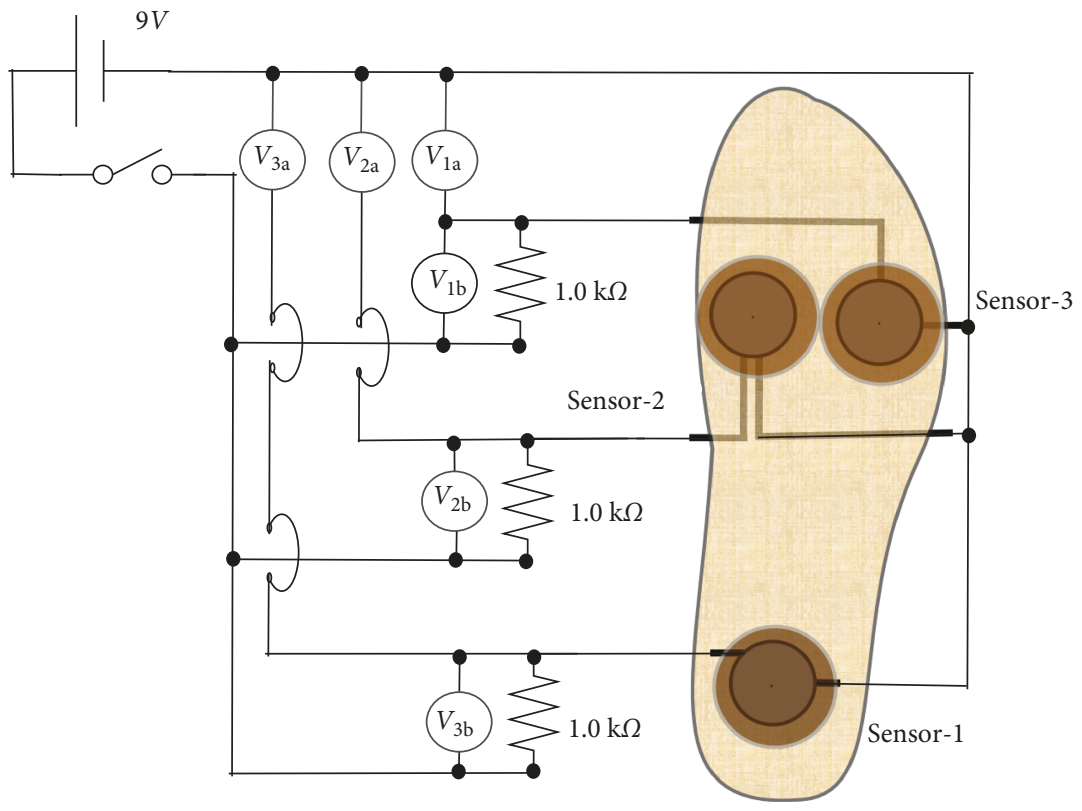

(b)

Figure 4: (a) Circuit used to measure the conductance of the load cell. (b) Circuit diagram for the insole-based load cells in the sole of a shoe in the foot pressure tests.

observed as shown in Figure 5(b). It can be seen that the spaces between the cotton fibers are large $(\sim 50 \mu \mathrm{m})$ under the force-free condition. Also, a small number of conduction paths exist between the electrodes, allowing the flow of electric current. However, when the MWCNT/cotton composite is pressed, its thickness decreases and the number of conduction paths increases owing to the increased number of contacts among the MWCNT/cotton fibers and surface of the electrodes (Figure 5(b)) [7]. Figure 5(b) shows that the cotton fibers are pressed close to each other when a force is applied. Part of Figure 5(b) is magnified and shown in Figure 5(c), where many MWCNTs densely cover the surface of the cotton fibers.

\subsection{Optimization of MWCNT/Cotton Composite for Use in a} Load Cell. To increase the conductance of the composite, the cotton is dipped into MWCNT ink several times. After the first dip, the mass and conductance of the MWCNT-coated cotton in the load cell are $0.200 \pm 0.004 \mathrm{~g}$ and $0.50 \mathrm{mS}$, respectively. The concentration of MWCNTs on the cotton after the first dip is $3.2 \mathrm{wt} \%$. Then, the cotton sample is dipped several times into the MWCNT ink. It is observed that the concentration of MWCNTs on the cotton sample increases with the number of dips. The concentration of the MWCNTs versus the number dips is shown in Figure 6(a).
With increasing concentration of MWCNTs, the electric conductance of the MWCNT-coated cotton is observed to increase considerably. The electric conductance as a function of the concentration of MWCNTs on the cotton is shown in Figure 6(b). The data are measured five times, and error bars are also shown. Here, the error (standard deviation) is defined as

$$
\varepsilon=\sqrt{\frac{\sum_{1}^{n}\left(x_{i}-x\right)^{2}}{n-1}}
$$

where $x_{\mathrm{i}}$ are measured physical values, $n$ is the number of samples, and $x=\sum_{1}^{n} x_{i} / n$.

To obtain appropriate MWCNT/cotton composites, different amounts of MWCNTs are coated on the cotton material. To obtain the highest sensitivity, four load cells are fabricated with different concentrations of $\mathrm{f}-\mathrm{MW}$ CNTs. Figure 7(a) shows the conductance $\sigma$ versus the force applied to the load cell for the four different concentrations of MWCNTs. It is observed that the conductance increases with increasing force from 1.0 to $50.0 \mathrm{~N}$. Increasing the concentration of MWCNTs coated on the cotton also increases the conductance. When a force is applied, the fibers of the composite are compressed, and the contact 


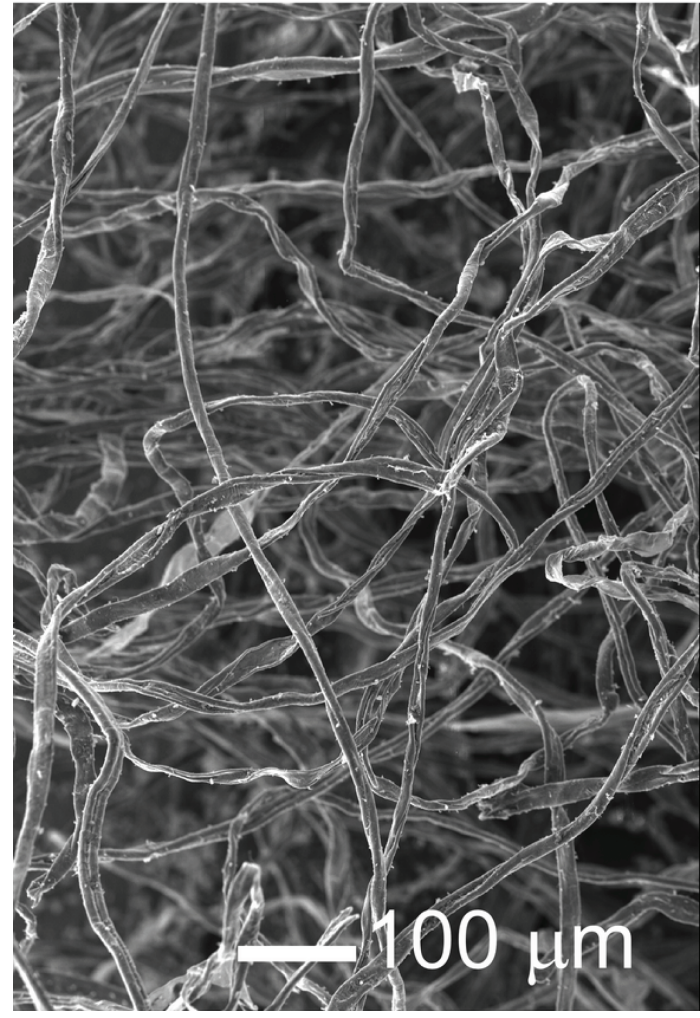

(a)

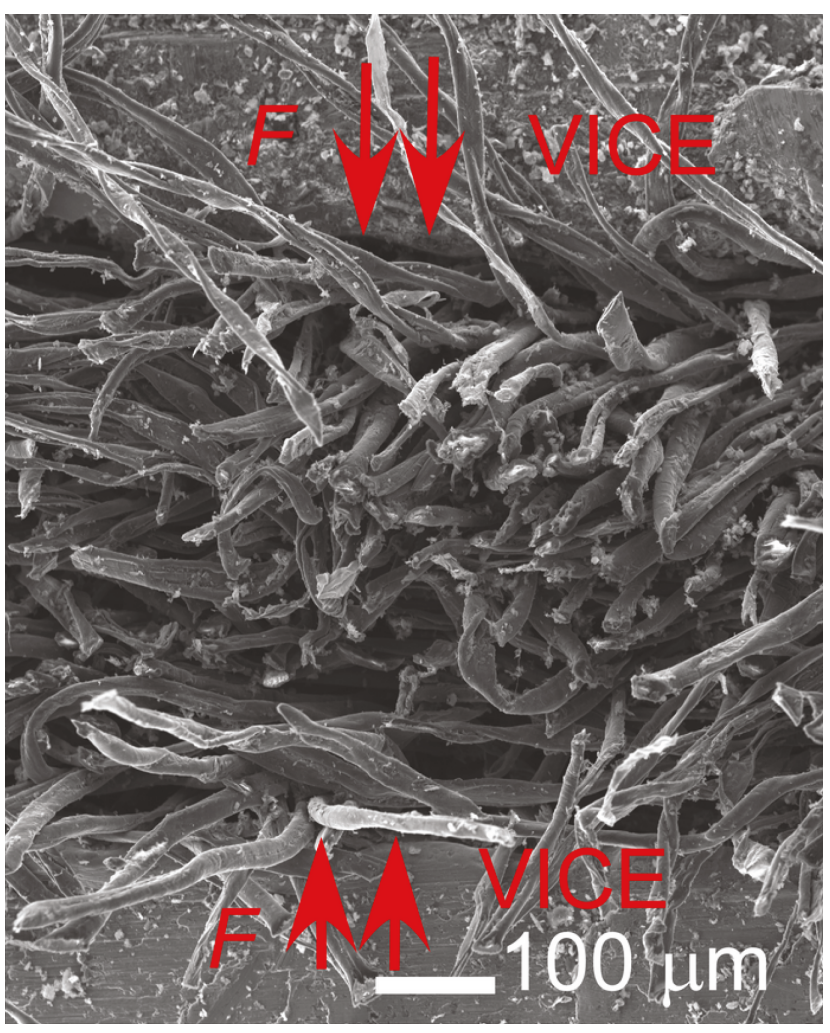

(b)

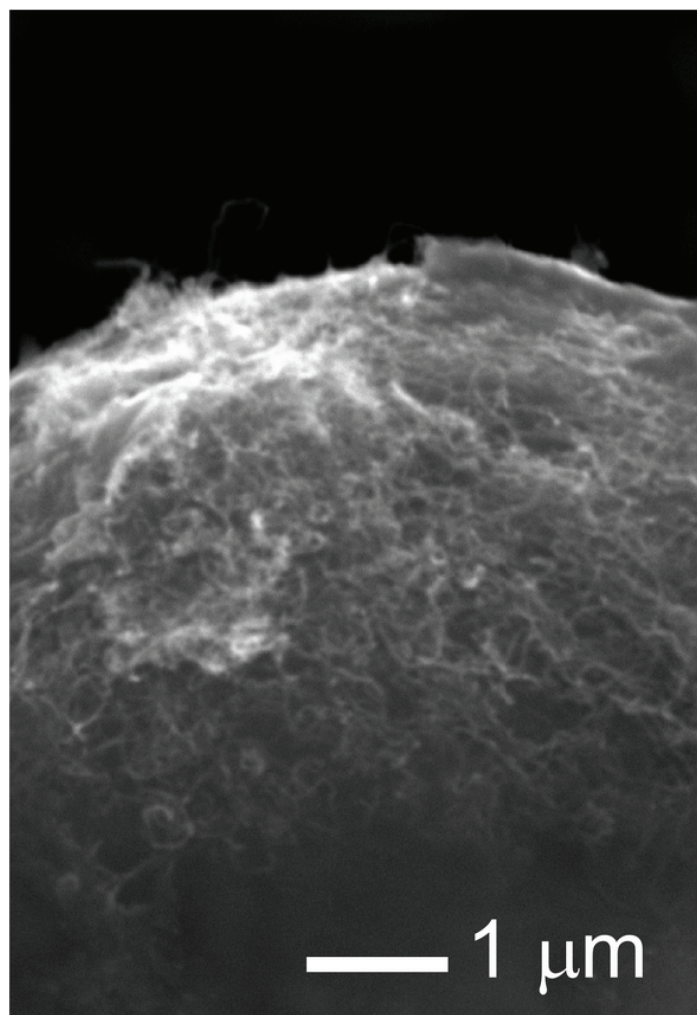

(c)

FIGURE 5: SEM images of an MWCNT/cotton composite. (a) Force-free condition, (b) composite pressed under a force of $10 \mathrm{~N}$, and (c) region of (b) focused and magnified at $\times 18,000$, where many MWCNTs are observed to be coated on the cotton fibers. 


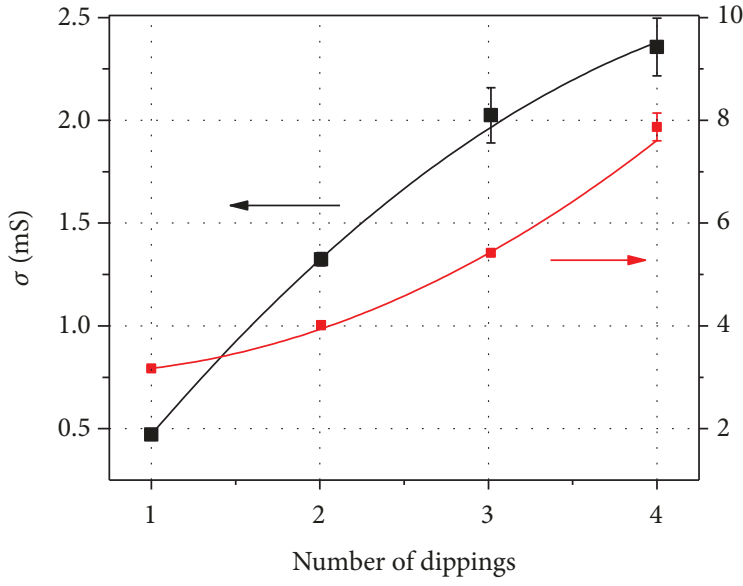

(a)

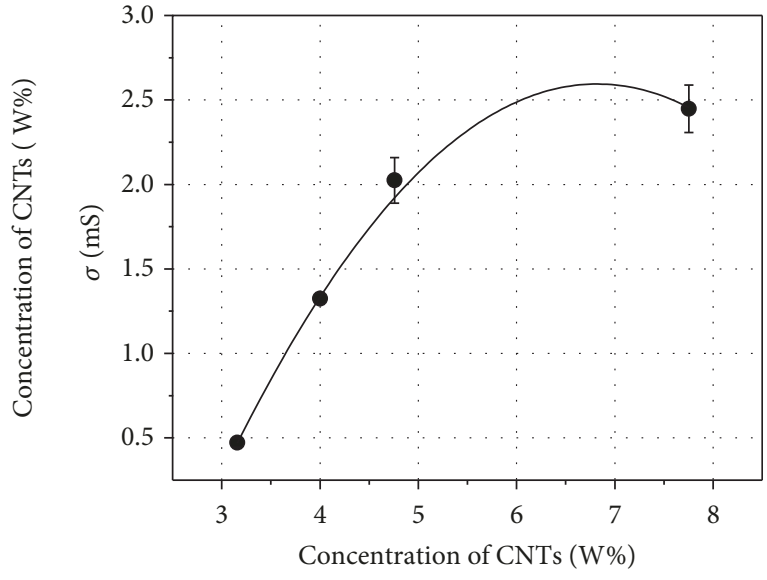

(b)

Figure 6: (a) Conductance and concentration of MWCNTs in the MWCNT/cotton composite versus number of dips. (b) Conductance versus concentration of MWCNTs in the MWCNT/cotton composite. Here, $F=1.0 \mathrm{~N}$.
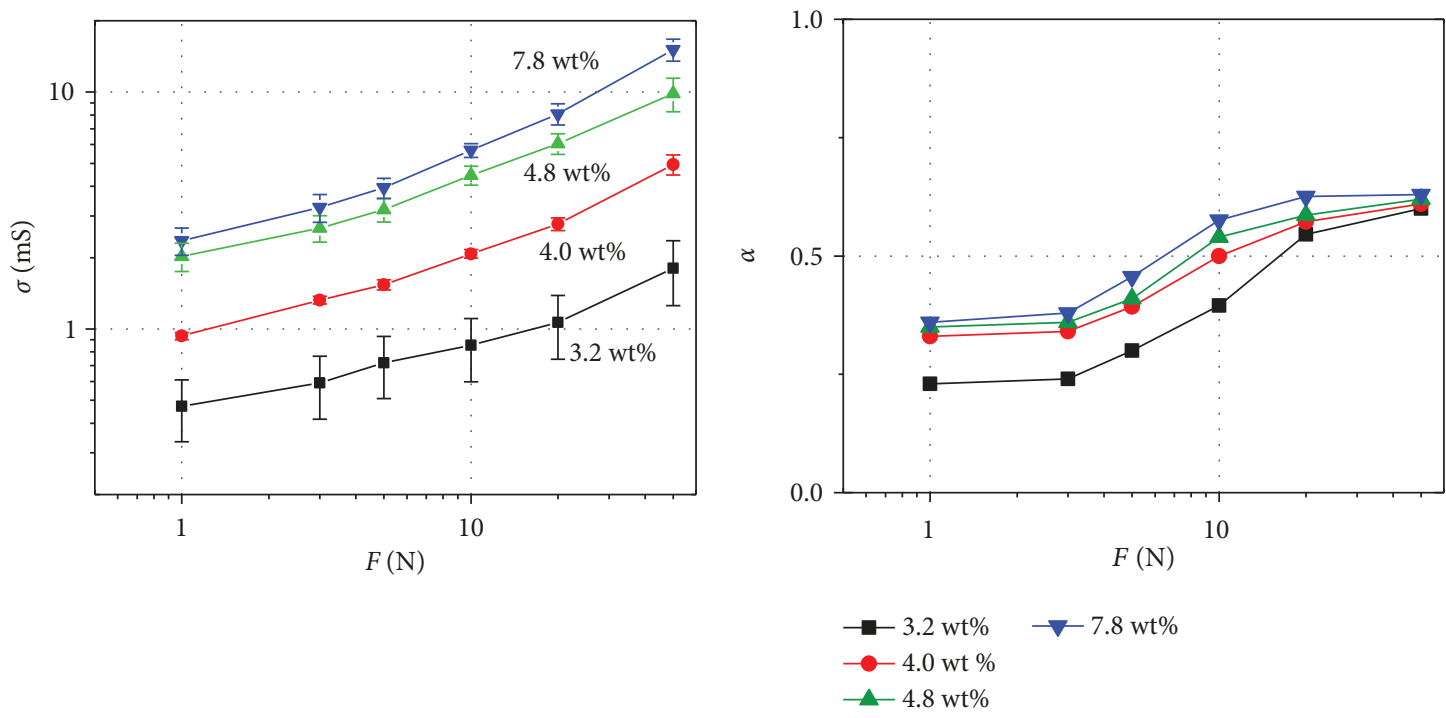

(a)

(b)

Figure 7: (a) Conductance versus force applied to the load cell for MWCNT concentrations of 3.2, 4.0, 4.8, and 7.8 wt $\%$. (b) $\alpha$ in equation (4) versus applied force for different MWCNT concentrations.

area among the MWCNT/cotton fibers and among the fibers and surface of the electrodes is increased, which increases the conductance of the composite. The following empirical relationship between $\sigma$ and the applied force $F$ $(F=1.0-50.0 \mathrm{~N})$ can be obtained from the characteristic of each load cell:

$$
\sigma \simeq A F^{\alpha}+B
$$

where $\sigma$ is the conductance and $A$ and $B$ are constants. $\alpha$ gradually increases with the applied force for each concentration of MWCNTs on the composite, as shown in Figure 7(b). $\alpha$ also increases with increasing concentration of MWCNTs. Here, $7.8 \mathrm{wt} \%$ MWCNTs and four dips are considered to be the optimum conditions for the experimental study, and these conditions are employed when fabricating the load cells.

Pristine cotton fibers are insulating, but when they are coated with f-MWCNTs, their electric conductance markedly increases. The conductance of the MWCNT/cotton composites increases from 0.47 to $2.4 \mathrm{mS}$ when the concentration of MWCNTs is increased from 3.2 to $7.8 \mathrm{wt} \%$ under an applied force of $1.0 \mathrm{~N}$. The conductance increases from 1.8 to $15 \mathrm{mS}$ under a force of $50.0 \mathrm{~N}$ when the concentration of MWCNTs is increased from 3.2 to $7.8 \mathrm{wt} \%$. The conductance versus $F$ curve becomes steeper, and the magnitude of the conductance becomes high when the concentration of MWCNTs exceeds the electron conduction threshold [41]. When the concentration of MWCNTs and the force are increased, the number of electron conduction paths in 
the sample also increases and the electric conductance increases significantly. The conductance of the load cell mainly depends on two type of contacts: (a) contact among the MWCNT/cotton fibers in the bulk of the composites (inside the composites of the load cell) and (b) contact between a surface of the electrodes and the surface of the MWCNT/cotton fibers. As the surfaces of the cotton fibers contain -OH groups and the factionalized MWCNTs also contain $-\mathrm{OH}$ and $-\mathrm{COOH}$ groups $[33,37]$, it is conjectured that weak hydrogen bonds are formed between the $f$ MWCNTs and the cotton fibers, which make a stable coating on cotton [37].

To obtain higher sensitivity, the conductance of the load cell as a function of the thickness of the composite is measured. The result is shown in Figure 8(a), where the conductance of the load cells is observed to decrease with increasing thickness, which is due to the increase in the distance between the two electrodes. The applied force is varied from 0.50 to $1000 \mathrm{~N}$, and the corresponding conductance is observed to increase from 0.087 to $25 \mathrm{mS}$. Note that the conductance of the load cell of $2.0 \mathrm{~mm}$ thickness is slightly higher than those of the other thicknesses, but the stability of the conductance is lower and the noise level is higher. Therefore, a thickness of $4.0 \mathrm{~mm}$ is employed in this experimental study. As the resistance $R$ mainly depends on the contact between the MWCNTs/cotton composites and thickness of composites $d$, the increase in resistance with increasing thickness is shown in Figure 8(b).

The negligible hysteresis of sensors is important for their actual use. The hysteresis curve of $\sigma$ versus $F$ is measured and shown in Figure 8(c), which indicates almost zero hysteresis of the load cell for $F=0-400 \mathrm{~N}$. The measurement is repeated, and good reproducibility is obtained. These characteristics indicate the validity of the empirical equation (4). When the applied force is increased from 0 to $500 \mathrm{~N}$, a small hysteresis in the $F-\sigma$ curves is observed. The compression and relaxation in this range $(0-500 \mathrm{~N})$ of force are also carried out 10 times, and a small hysteresis is observed. This type of hysteresis is considered to be due to the delayed recovery time of the sensor.

3.3. Sensitivity and Response Time of the Load Cell. Sensitivity and response time are two important parameters for the load cells, which can be measured by applying different quantities of force. The sensitivity of the sensors has already been defined in equation (1), where $R_{\mathrm{L}}$ is the resistance under a load, $R_{0}$ is the pressure-free resistance, and $\Delta p$ is the change in applied pressure. The applied force and pressure have the relation $p=F / A_{0}$, where $A_{0}$ is the surface area. Here, the surface area of the load cell is $1.13 \times 10^{-4} \mathrm{~m}^{2}$ (the diameter is $0.012 \mathrm{~m}$ ). The sensitivity of the load cell for various forces is measured and compared with previously reported values, as shown in Figure 9. The applied forces of $F=1$ $\mathrm{mN}-100 \mathrm{~N}$ correspond to pressures of $p=8.84 \mathrm{~Pa}-884 \mathrm{kPa}$, and the corresponding range of sensitivity is $S=180$ $-0.20 \mathrm{kPa}^{-1}$. These sensitivities are much higher than the previously reported values [12, 17-23, 27-29, 35, 42-47]. It can be seen that the sensitivity and pressure-sensing range of the MWCNT/cotton load cell in this work are the best among the reported values for the pressure sensors [12, 32, 42-47] shown in Figure 9. When $p=15-884 \mathrm{kPa}(F=1.7-100 \mathrm{~N})$, the sensitivity decreases gradually and $S=0.20 \mathrm{kPa}^{-1}$ at $p=884 \mathrm{kPa}(F=100 \mathrm{~N})$. However, this lower sensitivity at high pressures is still sufficient to measure the exact force.

The response time upon the application of a force is also an important parameter for any load cell. To determine the time response, a load of $5.0 \mathrm{~N}$ is used. The load is dropped directly onto the load cell from a height of $3.0 \mathrm{~cm}$, and the response time is measured by a digital data recorder. The load is then very quickly removed to determine the relaxation time. Here, the $50 \%$ relaxation time $\tau_{1 / 2}$ is measured. For all these measurements, the response and recovery times $\tau_{1 / 2}$ are 4.5 and $5.0 \mathrm{~ms}$, respectively, which are much shorter than the previously reported values $[44,48,49]$. In addition, the response of the load cell under repeated compression/relaxation cycles with frequencies of 0.20 to $1.0 \mathrm{~Hz}$ is measured, where a force of $2.0 \mathrm{~N}$ is repeatedly applied. The changes in the conductance under the application of a constant force are qualitatively similar for frequencies from 0.20 to $1.0 \mathrm{~Hz}$.

3.4. Stability and Reproducibility. To observe the reproducibility of the force measurements, five different load cells with the same size and same amount of MWCNT/cotton composites are tested. As shown in Figure 10(a), it is observed that the rates of increase in the conductance are almost the same for all the load cells, and the $\sigma$ versus $F$ curves follow the empirical equation (4), which confirms their high reproducibility. However, $\alpha$ increases gradually with increasing force, which is shown in Figure 10(b). The measurement errors calculated by equation (3) are also shown in the graph.

To observe the stability, lifetime, and reproducibility of the load cells, additional tests are carried out. The sturdiness of the cell is tested by the long-time repetition of loading and unloading, and the result is shown in Figure 11. A force of $2.0 \mathrm{~N}$ is used to perform the test for about $3.1 \mathrm{~h}$. The loading cycle is 60 times per min. During the loading-unloading cycle tests, the response signals are not disturbed and the changes in $\sigma$ are almost negligible after 11,200 cycles, indicating that the load cell can be expected to be highly reliable in repeated use. Two regions in the time chart are selected randomly and shown in Figure 11(a) $(t=1100-1120 \mathrm{~s})$ and Figure 11(b) ( $t=10980-11000 \mathrm{~s})$, where the sampling rate is 10 samples/s.

Next, the load cell is treated at a temperature in the range of -20 to $80^{\circ} \mathrm{C}$ while loading and unloading a force of $2.0 \mathrm{~N}$. It is observed from Figure 12(a) that the conductance slightly increases with the temperature during both the on-time and off-time of the applied load, which indicates that the cell operates normally under low- and high-temperature conditions. Because the conductance changes with the net contact area among the MWCNT-coated cotton fibers upon applying a force, the ambient temperature does not strongly affect the efficiency of the cells. This effect was also reported in ref. [45]. It is also observed that even when a load of $2.0 \mathrm{~N}$ is applied for a long time at harsh temperatures, the conductance remains almost constant. When the load cell is kept at $-20^{\circ} \mathrm{C}$ for $24 \mathrm{~h}$, it is observed that the conductance remains almost the same. After that, when the cell is kept at $80^{\circ} \mathrm{C}$ for $24 \mathrm{~h}$, the same result is obtained, as shown in 


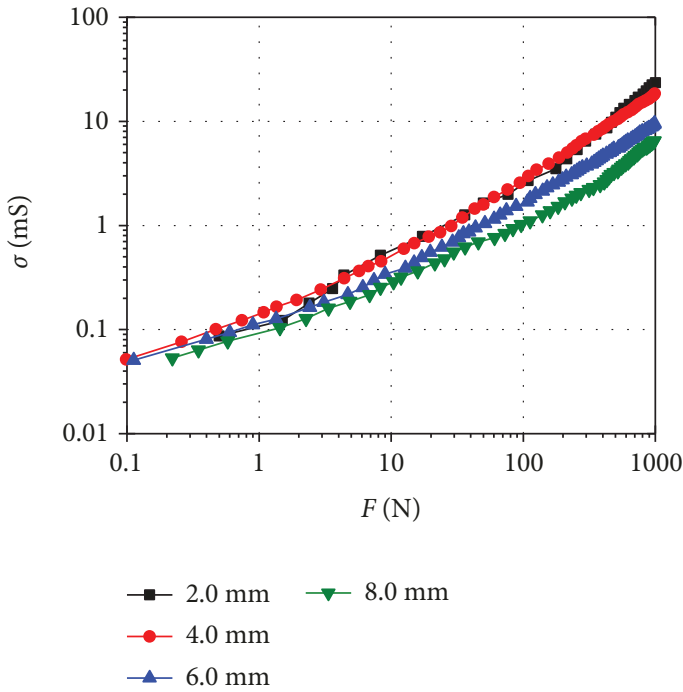

(a)

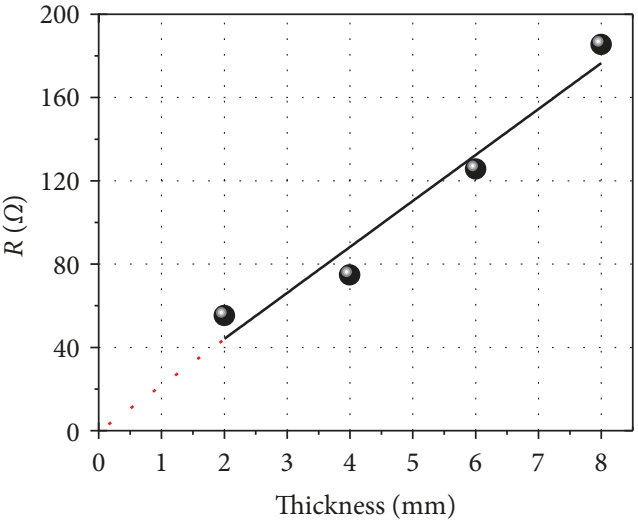

(b)

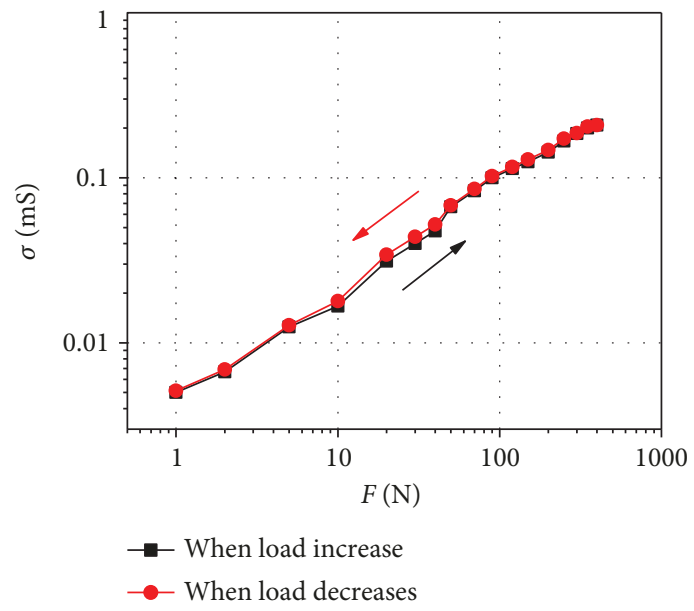

(c)

FiguRE 8: (a) Conductance $\sigma$ versus applied force $F$ for composite thicknesses of 2.0, 4.0, 6.0, and 8.0 mm. (b) Resistance $R$ versus thickness of the MWCNT/cotton composite. (c) Hysteresis characteristic of the load cell, where $F$ is changed from 1.0 to $400 \mathrm{~N}$.

Figure 12(c). Therefore, it is confirmed that the cell is stable at both low and high temperatures $\left(T=-20-80^{\circ} \mathrm{C}\right)$. The loading and unloading of a force of $2.0 \mathrm{~N}$ are also carried out under different humidity conditions. The change in the conductance during the loading and unloading of the force remains almost the same up to a humidity of $80 \%$, as shown in Figure 12(b). However, a slight change is observed when the humidity is above $90 \%$. It is conjectured that when the humidity exceeds $90 \%$, some vapor condenses and wets the load cell. The load cell is kept at more than $90 \%$ humidity for $24 \mathrm{~h}$, then the humidity is decreased to the normal value. After that, no significant change is observed in the conductance. To test the reproducibility of the load cell, it is soaked in pure water for $24 \mathrm{~h}$, then the conductance is measured. When it is soaked in the water, the conductance increases slightly owing to the incorporation of the water in the cell. After $24 \mathrm{~h}$ of soaking, followed by drying, the conductance of the cell recovers and the cell works well which is written as the value of conductance after treatment and shown in Figure 12(c).

The load cell can also work well when a large weight is applied. A load of $1.0 \mathrm{kN}$ is applied on the cell for $24 \mathrm{~h}$, and the initial conductance is measured to be $10.6 \mathrm{mS}$, whereas it is $11.3 \mathrm{mS}$ after $24 \mathrm{~h}$, as shown in Figure 12(d). This process is repeated, and high reproducibility is confirmed.

From Figures 7(a) and 8(a), the load cell satisfies equation (4) with $\sigma$ almost proportional to the surface area $A_{0}$ and $1 / d$ ( $d$ = thickness of the composite).

3.5. Monitoring of Pressure on Human Sole. As an application of the load cell, a set of pressure sensors is developed to monitor the pressure on human soles during walking, jogging, and standing. Three load cells are installed in the soft sole of a shoe, as shown in Figure 3. The pressure-monitoring circuit is shown in Figure 4, where the resistances of these sensors are recorded. Time variations of the forces are recorded when 


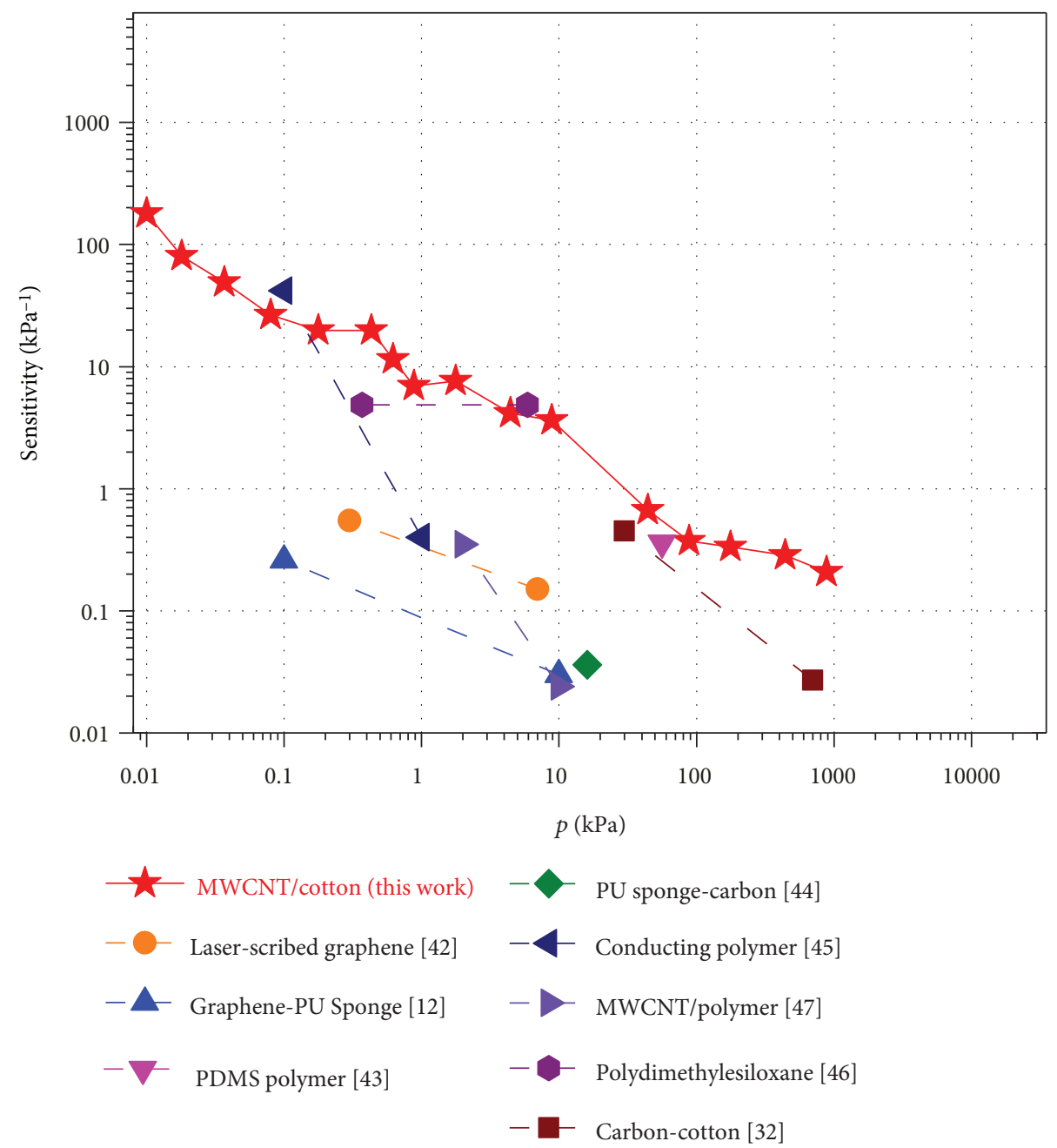

FIGURE 9: Sensitivity versus corresponding pressure and comparison of the sensitivity of the load cell with those for previously reported pressure sensors.

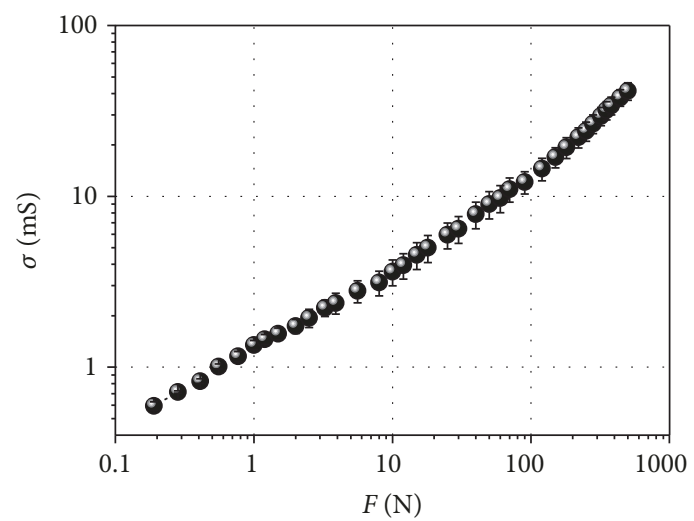

(a)

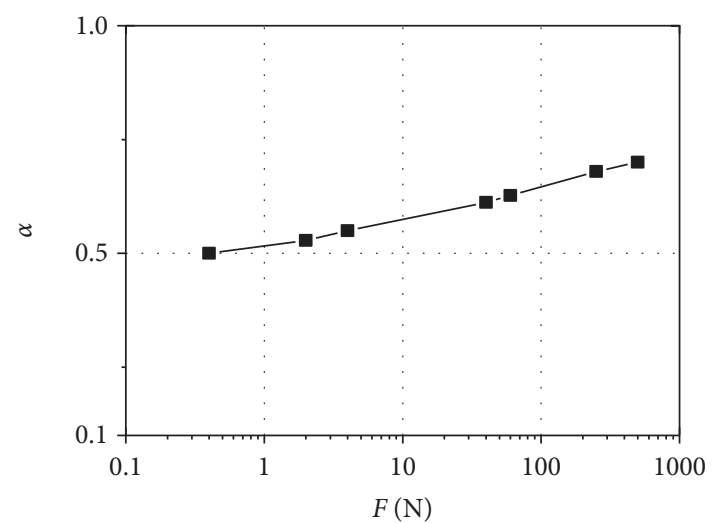

(b)

Figure 10: (a) Reproducibility test using five load cells with the same size and same amount of MWCNT/cotton composites. (b) Applied force versus $\alpha$ when $F=0-500 \mathrm{~N}$, showing a slight change in $\alpha$.

a healthy person is walking or jogging. Figures 13(a) and 13(b) show the time variation of the forces on the load cells on the sole during walking and jogging at 43 and 90 steps per minute, respectively. Every peak shown in Figures 13(a) and 13(b) corresponds to an individual step during walking and jogging, respectively. The forces on the sensors 


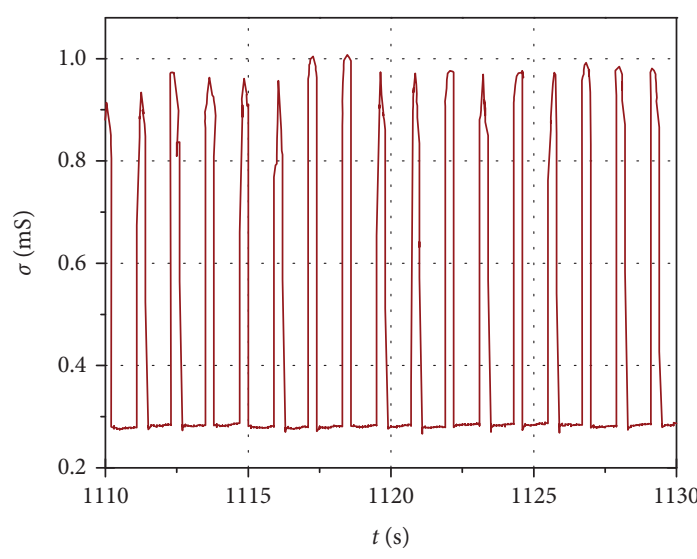

(a)

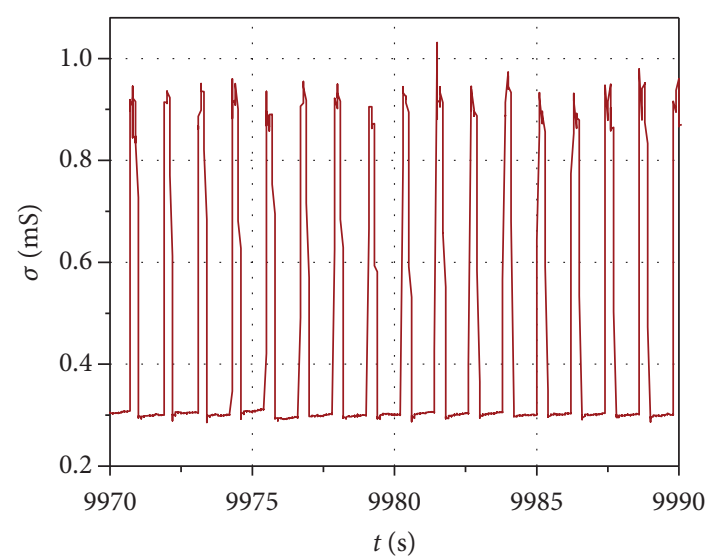

(b)

FIgURE 11: Durability test of the load cell involving 11,200 cycles of compression and relaxation, where $F=2.0 \mathrm{~N}$. Variations of conductance $\sigma$ in (a) an early time period and (b) a late time period. The two wave-forms do not show any significant differences.

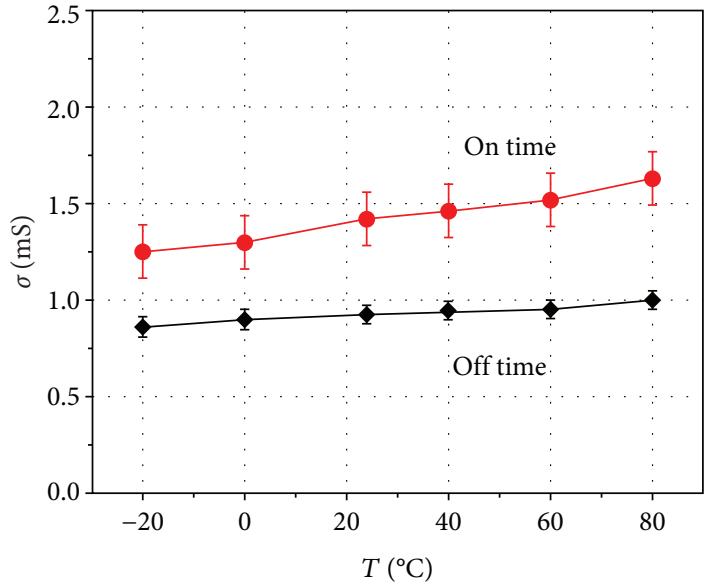

(a)

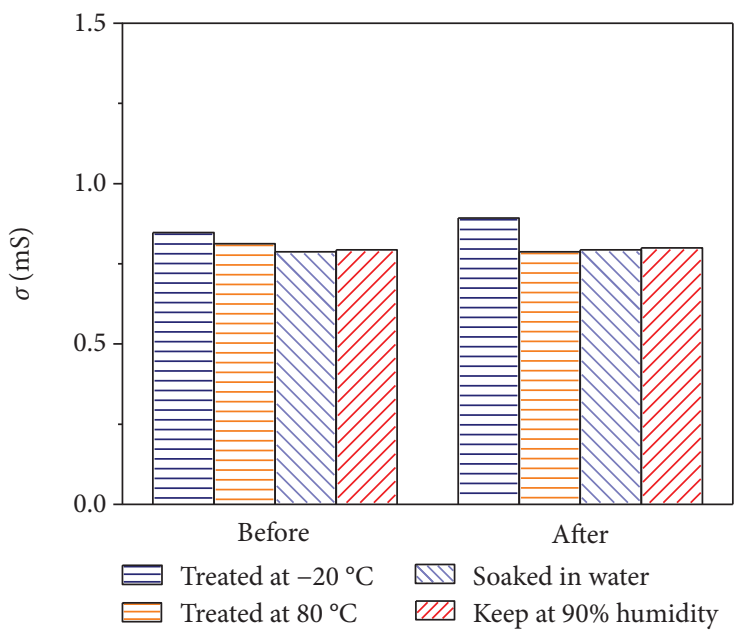

(c)

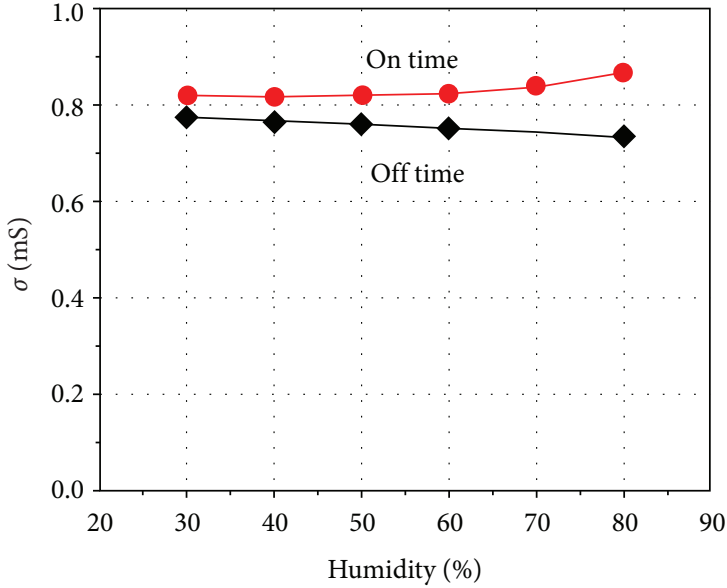

(b)

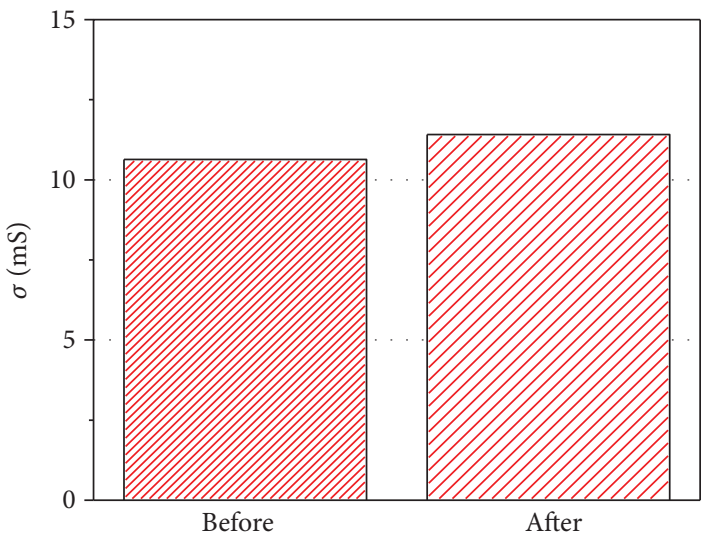

(d)

FIGURE 12: (a) Conductance versus sample treatment temperature from -20 to $80^{\circ} \mathrm{C}$, where $F=2.0 \mathrm{~N}$. (b) Conductance versus humidity, where $F=2.0 \mathrm{~N}$. (c) Reproducibility of the conductance of the load cell treated at -20 and $80^{\circ} \mathrm{C}$, soaked in pure water for $24 \mathrm{~h}$, then kept at above $90 \%$ humidity. (d) Conductance measured when a load of $F=1.0 \mathrm{kN}$ is first applied and conductance after the application of $F=1.0 \mathrm{kN}$ for $24 \mathrm{~h}$. 


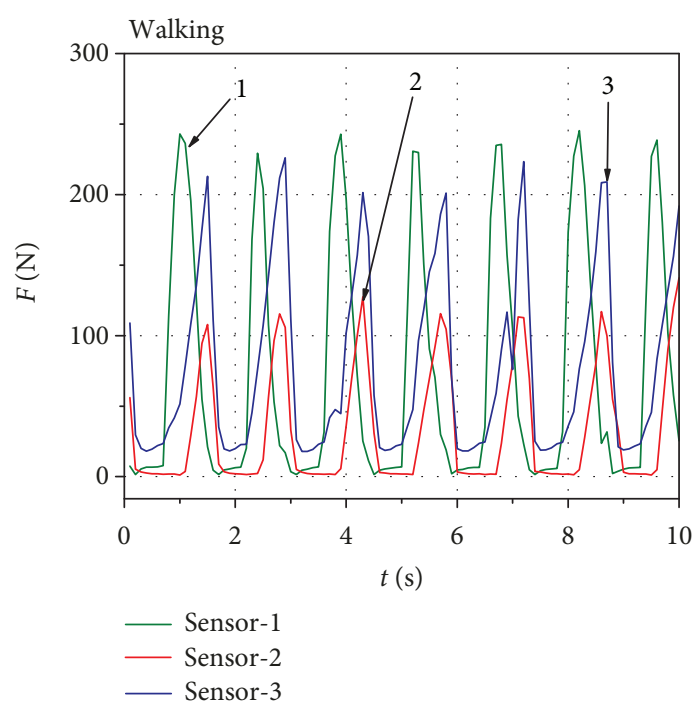

(a)

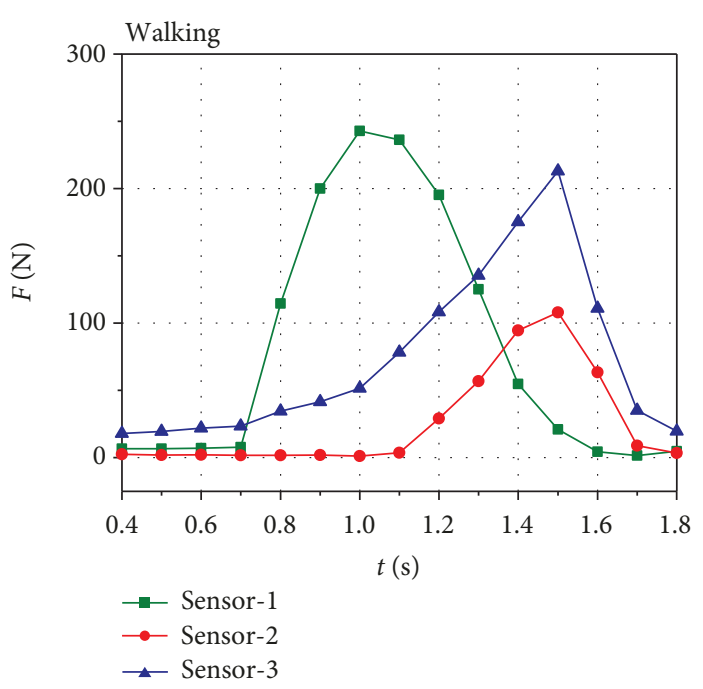

(c)

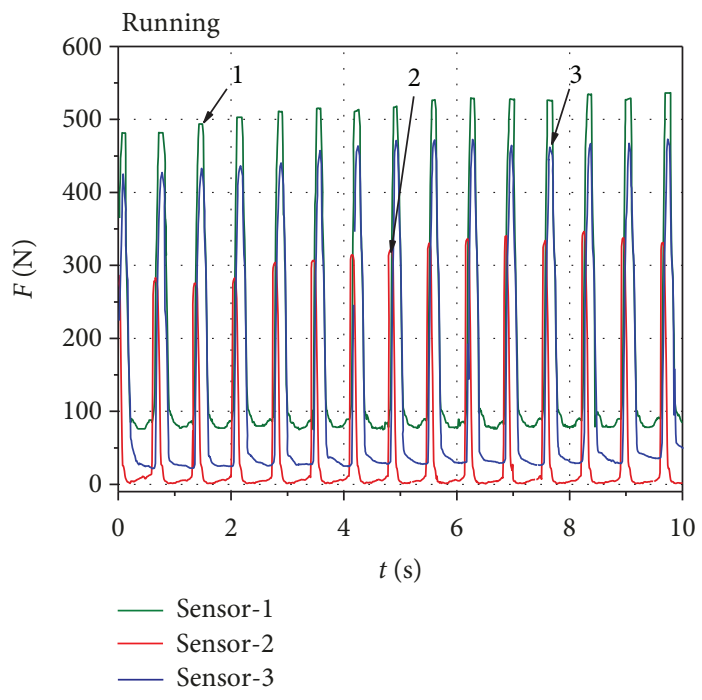

(b)

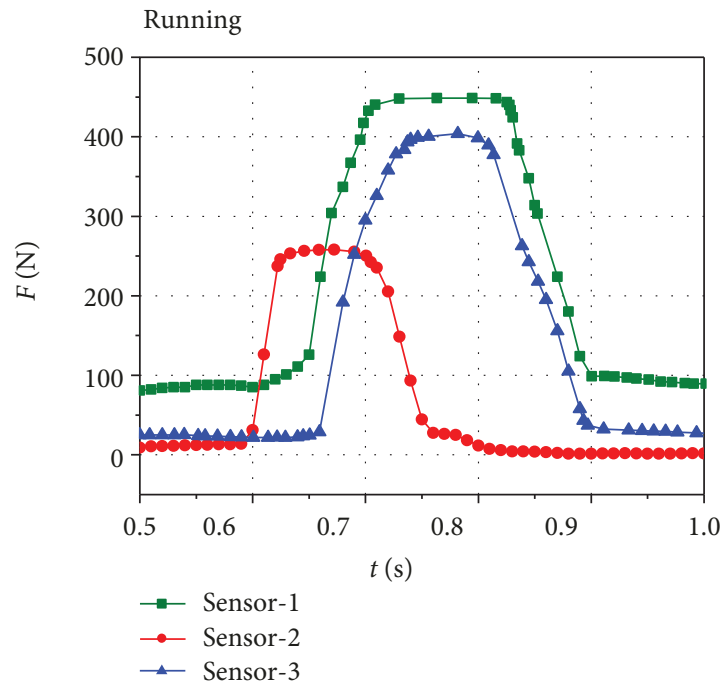

(d)

FIgUre 13: $(a, c)$ Time variations of the forces on the load cells set in a shoe during walking. (b, d) Time variations of the forces during jogging.

are calculated using a set of calibrated data. It is observed from Figures 13(c) and 13(d) that sensor 1 records the strongest force among the sensors. In addition, the force propagates from sensors 1 and 2 to sensor 3 during jogging. The forces on sensors 2 and 3 are similar for a short duration during jogging.

3.6. Monitoring the Center of Gravity of a Human Foot while Standing. In the standing position, the weight of a human body is supported by the two feet, and balancing is necessary. To observe the balance of a person and the center of gravity when standing on one foot, an experiment is performed using the shoe sole pressure sensors. When a person stands on one foot, the body has to move slightly to maintain the balance. The changes in the center of gravity of the body caused by such movement create a locus of the footprint. When a person stands on one leg with eyes open, it is easy to balance the body and the center of gravity remains within a small area. However, when a person stands on one leg with eyes closed, it is difficult to balance the body, and thus the center of gravity changes quickly and widely. Figures 14(a) and 14(b) show the time variation of the forces on the three sensors when the healthy man employed in our experiment is standing on one foot with eyes open and closed, respectively. The force is calculated using the calibration data, and the center of gravity of the footprint $\left(X_{\mathrm{g}}, Y_{\mathrm{g}}\right)$ is calculated using the following equations:

$$
\begin{aligned}
& X_{g}=\frac{f_{2} x_{2}+f_{3} x_{3}}{f_{1}+f_{2}+f_{3}}, \\
& Y_{g}=\frac{f_{2} y_{2}+f_{3} y_{3}}{f_{1}+f_{2}+f_{3}},
\end{aligned}
$$

where $f_{1}, f_{2}$, and $f_{3}$ are the forces exerted on sensor 1 , sensor 2 , and sensor 3 , respectively. $x_{2}$ and $x_{3}$ are the $X$ positions of 


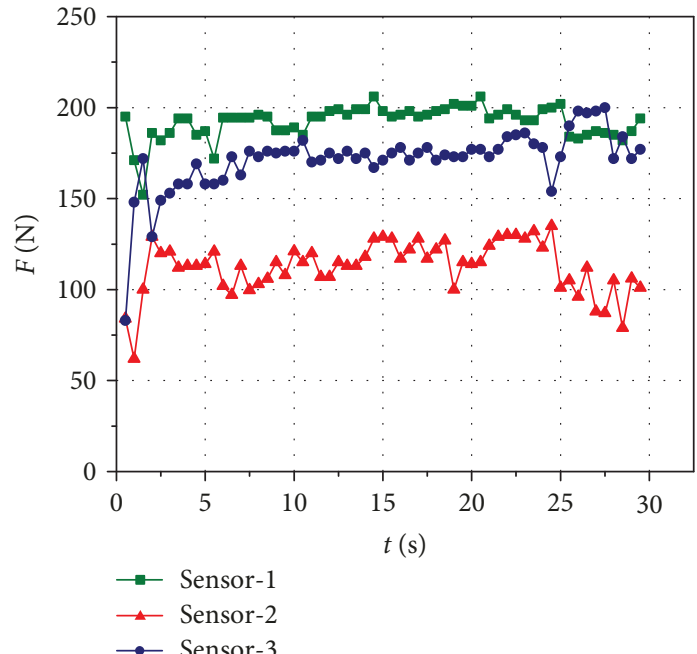

(a)

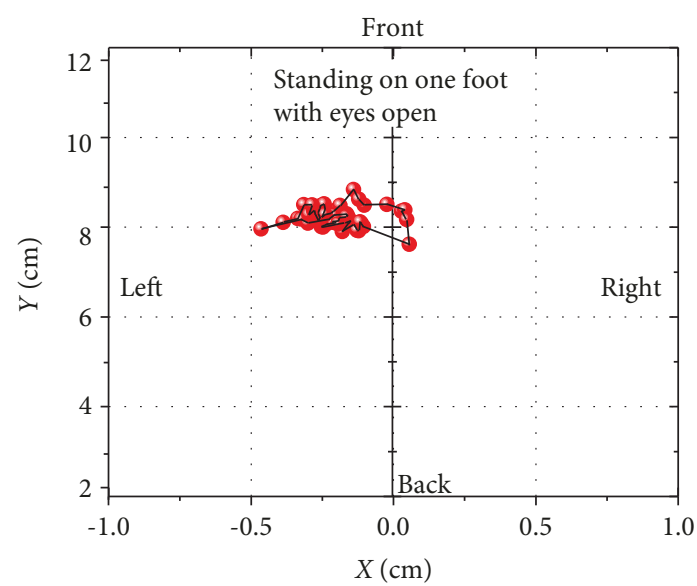

(c)

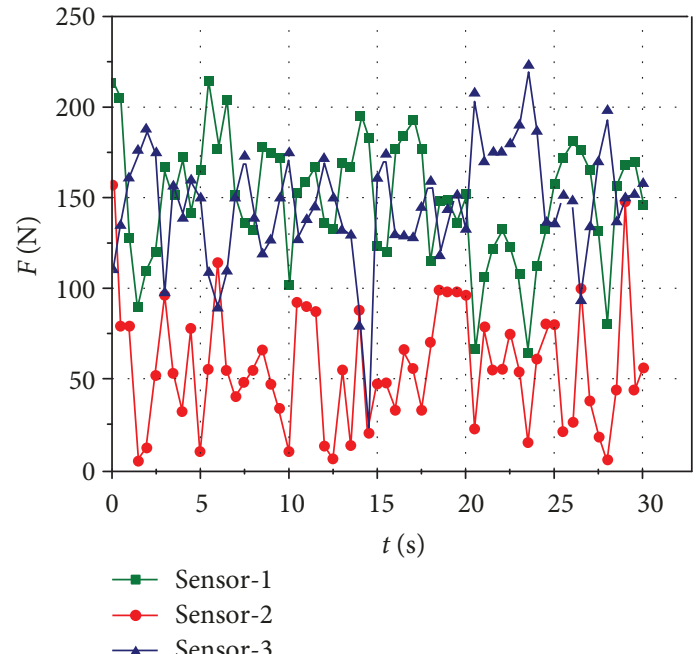

(b)

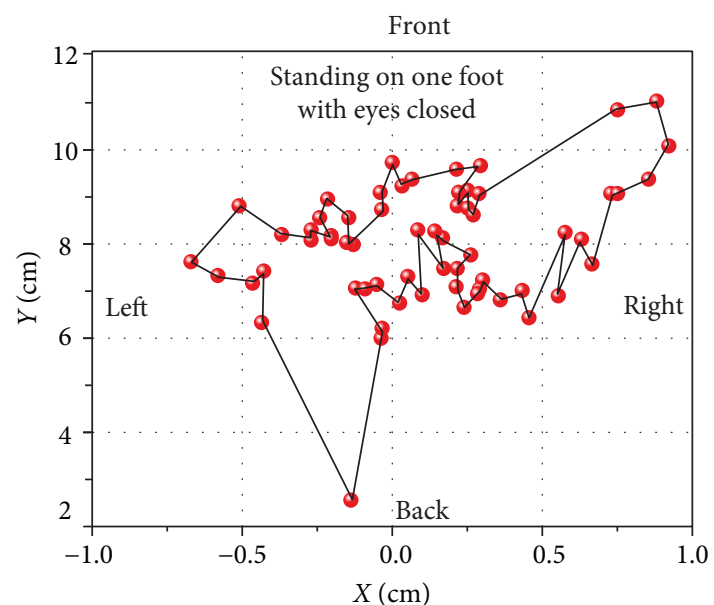

(d)

FIgURE 14: Time variation of the load while (a) standing on one foot with eyes open and (b) standing on one foot with eyes closed. Position of the center of gravity of a human foot while standing on one foot for $30 \mathrm{~s}$ (c) with eyes open and (d) with eyes closed. $(X, Y)=(0,0)$ is the position of sensor 1 .

the centers of sensor 2 and sensor 3 relative to the position of sensor 1 , respectively. Note that as the center of sensor 1 is set as the origin $\left(x_{1}, y_{1}\right)=(0,0)$, the positions of sensor 2 and sensor 3 are $\left(x_{2}, y_{2}\right)=(1.4 \mathrm{~cm}, 14 \mathrm{~cm})$ and $\left(x_{3}, y_{3}\right)=(-3.0$ $\mathrm{cm}, 13.4 \mathrm{~cm})$, respectively. It is observed from Figure 14(c) that the variation of the center of gravity when the eyes are open is small, while the center of gravity moves frequently and extensively when the eyes are closed, as shown in Figure 14(d). Using this method, it is possible to monitor the time variation of the center of gravity. These measurements suggest that this method can be extended to monitor the balance of patients and people undergoing rehabilitation.

\section{Conclusions}

MWCNT/cotton load cells have been developed through simple, cost-effective, and eco-friendly processes. The MWCNT/cotton load cells show high sensitivity of about
$180-0.20 \mathrm{kPa}^{-1}$ when subjected to a pressure of $p=8.84 \mathrm{~Pa}$ $-884 \mathrm{kPa}(F=1.0 \mathrm{mN}-100 \mathrm{~N})$, which is sufficient to precisely detect the basic movements of human and real-time sports performances. The MWCNT/cotton load cells show high reproducibility in different harsh environments. The efficiency of the sensors remains almost the same at low and high temperatures and under low- and high-humidity conditions. The load cell shows short response and relaxation times $\left(\tau_{1 / 2}\right)$ of about 4.5 and $5 \mathrm{~ms}$, respectively, and almost zero hysteresis is observed. The load cells can measure characteristic signals corresponding to walking, jogging, and standing conditions. An important application of the load cells is to measure the center of gravity of a human foot, which can be used to monitor sick, old, or rehabilitating people. As the load cell is compact and the MWCNT composites are enclosed in plastic tapes, so MWCNTs do not diffuse and do not effect human skin. Therefore, the load cells have 
strong potential to be used as wearable force- (or pressure-) monitoring devices, for healthcare tests, rehabilitation, realtime sports activities, and robot technologies.

\section{Data Availability}

The data used to support the findings of this study are included within the article.

\section{Conflicts of Interest}

The authors declare that there is no conflict of interest regarding the publication of this paper.

\section{Acknowledgments}

This study was financially supported by Graduate School of Science and Technology, National University Corporation, Shizuoka University, Japan. The authors thank the Research Institute of Green Science and Technology, Shizuoka University, for the use of the SEM facility.

\section{References}

[1] S. Iijima, "Helical microtubules of graphitic carbon," Nature, vol. 354, no. 6348, pp. 56-58, 1991.

[2] P. J. F. Harris, Carbon Nanotube Science, Cambridge University Press, Cambridge, UK, 2013.

[3] A. Javey, J. Guo, D. B. Farmer et al., "Self-aligned ballistic molecular transistors and electrically parallel nanotube arrays," Nano Letters, vol. 4, no. 7, pp. 1319-1322, 2004.

[4] P. M. Ajayan, "Nanotubes from carbon," Chemical Reviews, vol. 99, no. 7, pp. 1787-1800, 1999.

[5] N. G. Sahoo, S. Rana, J. W. Cho, L. Li, and S. H. Chan, "Polymer nanocomposites based on functionalized carbon nanotubes," Progress in Polymer Science, vol. 35, no. 7, pp. 837867, 2010.

[6] Y. Liu and S. Kumar, "Polymer/carbon nanotube nano composite fibers-a review," ACS Applied Materials \& Interfaces, vol. 6, no. 9, pp. 6069-6087, 2014.

[7] A. S. Zuruzi, T. M. Haffiz, D. Affidah, A. Amirul, A. Norfatriah, and M. H. Nurmawati, "Towards wearable pressure sensors using multiwall carbon nanotube/polydimethylsiloxane nanocomposite foams," Materials \& Design, vol. 132, pp. 449-458, 2017.

[8] M. M. Rodgers, V. M. Pai, and R. S. Conroy, "Recent advances in wearable sensors for health monitoring," IEEE Sensors Journal, vol. 15, no. 6, pp. 3119-3126, 2015.

[9] N. Lu, C. Lu, S. Yang, and J. Rogers, "Highly sensitive skinmountable strain gauges based entirely on elastomers," Advanced Functional Materials, vol. 22, no. 19, pp. 40444050, 2012.

[10] C. Pang, C. Lee, and K. Y. Suh, "Recent advances in flexible sensors for wearable and implantable devices," Journal of Applied Polymer Science, vol. 130, no. 3, pp. 1429-1441, 2013.

[11] D. Kwon, T. I. Lee, J. Shim et al., "Highly sensitive, flexible, and wearable pressure sensor based on a giant piezocapacitive effect of three-dimensional microporous elastomeric dielectric layer," ACS Applied Materials \& Interfaces, vol. 8, no. 26, pp. 16922-16931, 2016.
[12] H. B. Yao, J. Ge, C. F. Wang et al., "A flexible and highly pressure-sensitive graphene-polyurethane sponge based on fractured microstructure design," Advanced Materials, vol. 25, no. 46, pp. 6692-6698, 2013.

[13] M. Amjadi, A. Pichitpajongkit, S. Lee, S. Ryu, and I. Park, "Highly stretchable and sensitive strain sensor based on silver nanowire-elastomer nanocomposite," ACS Nano, vol. 8, no. 5, pp. 5154-5163, 2014.

[14] D. Trivedi, C. D. Rahn, W. M. Kier, and I. D. Walker, "Soft robotics: biological inspiration, state of the art, and future research," Applied Bionics and Biomechanics, vol. 5, no. 3, 117 pages, 2008.

[15] R. Pfeifer, M. Lungarella, and F. Iida, "The challenges ahead for bio-inspired "soft" robotics," Communications of the ACM, vol. 55, no. 11, pp. 76-87, 2012.

[16] C. Dagdeviren, Y. Su, P. Joe et al., "Conformable amplified lead zirconate titanate sensors with enhanced piezoelectric response for cutaneous pressure monitoring," Nature Communications, vol. 5, no. 1, p. 4496, 2014.

[17] A. V. Shirinov and W. K. Schomburg, "Pressure sensor from a PVDF film," Sensors and Actuators A: Physical, vol. 142, no. 1, pp. 48-55, 2008.

[18] W. Wu, X. Wen, and Z. L. Wang, "Taxel-addressable matrix of vertical-nanowire piezotronic transistors for active and adaptive tactile imaging," Science, vol. 340, no. 6135, pp. 952-957, 2013.

[19] C. Metzger, E. Fleisch, J. Meyer et al., "Flexible-foam-based capacitive sensor arrays for object detection at low cost," Applied Physics Letters, vol. 92, no. 1, article 013506, 2008.

[20] H. K. Lee, S. I. Chang, and E. Yoon, "A flexible polymer tactile sensor: fabrication and modular expandability for large area deployment," Journal of Microelectromechanical Systems, vol. 15, no. 6, pp. 1681-1686, 2006.

[21] Q. Cao, S. H. Hur, Z. T. Zhu et al., "Highly bendable, transparent thin-film transistors that use carbon-nanotube-based conductors and semiconductors with elastomeric dielectrics," Advanced Materials, vol. 18, no. 3, pp. 304-309, 2006.

[22] X. Wang, Y. Gu, Z. Xiong, Z. Cui, and T. Zhang, "Silk-molded flexible, ultrasensitive, and highly stable electronic skin for monitoring human physiological signals," Advanced Materials, vol. 26, no. 9, pp. 1336-1342, 2014.

[23] S. Zhao, G. Zhang, Y. Gao et al., "Strain-driven and ultrasensitive resistive sensor/switch based on conductive alginate/nitrogen-doped carbon-nanotube-supported Ag hybrid aerogels with pyramid design," ACS Applied Materials \& Interfaces, vol. 6, no. 24, pp. 22823-22829, 2014.

[24] T. Yamada, Y. Hayamizu, Y. Yamamoto et al., "A stretchable carbon nanotube strain sensor for human-motion detection," Nature Nanotechnology, vol. 6, no. 5, pp. 296-301, 2011.

[25] K. Takei, T. Takahashi, J. C. Ho et al., "Nanowire active-matrix circuitry for low-voltage macroscale artificial skin," Nature Materials, vol. 9, no. 10, pp. 821-826, 2010.

[26] C. Pang, G. Y. Lee, T. I. Kim et al., "A flexible and highly sensitive strain-gauge sensor using reversible interlocking of nanofibres," Nature Materials, vol. 11, no. 9, pp. 795-801, 2012.

[27] I. Graz, M. Kaltenbrunner, C. Keplinger et al., "Flexible ferroelectret field-effect transistor for large-area sensor skins and microphones," Applied Physics Letters, vol. 89, no. 7, article 073501, 2006.

[28] S. Chen, B. Zhuo, and X. Guo, "Large area one-step facile processing of microstructured elastomeric dielectric film for high 
sensitivity and durable sensing over wide pressure range," ACS Applied Materials \& Interfaces, vol. 8, no. 31, pp. 20364-20370, 2016.

[29] S. Gong, W. Schwalb, Y. Wang et al., "A wearable and highly sensitive pressure sensor with ultrathin gold nanowires," Nature Communications, vol. 5, no. 1, 2014.

[30] A. Moisala, Q. Li, I. A. Kinloch, and A. H. Windle, "Thermal and electrical conductivity of single- and multi-walled carbon nanotube-epoxy composites," Composites Science and Technology, vol. 66, no. 10, pp. 1285-1288, 2006.

[31] Y. Q. Li, P. Huang, W. B. Zhu, S. Y. Fu, N. Hu, and K. Liao, "Flexible wire-shaped strain sensor from cotton thread for human health and motion detection," Scientific Reports, vol. 7, no. 1, article 45013, 2017.

[32] Y. Li, Y. A. Samad, and K. Liao, "From cotton to wearable pressure sensor," Journal of Materials Chemistry A, vol. 3, no. 5, pp. 2181-2187, 2015.

[33] M. J. Rahman and T. Mieno, "Water-dispersible multiwalled carbon nanotubes obtained from citric-acid-assisted oxygen plasma functionalization," Journal of Nanomaterials, vol. 2014, Article ID 508192, 9 pages, 2014.

[34] D. Tasis, N. Tagmatarchis, A. Bianco, and M. Prato, "Chemistry of carbon nanotubes," Chemical Reviews, vol. 106, no. 3, pp. 1105-1136, 2006.

[35] S. Hussain, R. Amade, E. Jover, and E. Bertran, "Functionalization of carbon nanotubes by water plasma," Nanotechnology, vol. 23, no. 38, article 385604, 2012.

[36] A. Hirsch and O. Vostrowsky, "Functionalization of carbon nanotubes," Topics in Current Chemistry, vol. 245, pp. 193237, 2005.

[37] M. J. Rahman and T. Mieno, "Conductive cotton textile from safely functionalized carbon nanotubes," Journal of Nanomaterials, vol. 2015, Article ID 978484, 10 pages, 2015.

[38] L. Zheng, X. Zhang, Q. Li et al., "Carbon-nanotube cotton for large-scale fibers," Advanced Materials, vol. 19, no. 18, pp. 2567-2570, 2007.

[39] N. J. Saikia, C. Ewels, J. F. Colomer et al., "Plasma fluorination of vertically aligned carbon nanotubes," Journal of Physical Chemistry C, vol. 117, no. 28, pp. 14635-14641, 2013.

[40] D. S. Hecht, L. Hu, and G. Grüner, "Electronic properties of carbon nanotube/fabric composites," Current Applied Physics, vol. 7, no. 1, pp. 60-63, 2007.

[41] J. K. W. Sandler, J. E. Kirk, I. A. Kinloch, M. S. P. Shaffer, and A. H. Windle, "Ultra-low electrical percolation threshold in carbon-nanotube-epoxy composites," Polymer, vol. 44, no. 19, pp. 5893-5899, 2003.

[42] H. Tian, Y. Shu, X. F. Wang et al., "A graphene-based resistive pressure sensor with record-high sensitivity in a wide pressure range," Scientific Reports, vol. 5, no. 1, p. 8603, 2015.

[43] G. Schwartz, B. C. K. Tee, J. Mei et al., "Flexible polymer transistors with high pressure sensitivity for application in electronic skin and health monitoring," Nature Communications, vol. 4, no. 1, p. 1859, 2013.

[44] X. Wu, Y. Han, X. Zhang, Z. Zhou, and C. Lu, "Large-area compliant, low-cost, and versatile pressure-sensing platform based on microcrack-designed carbon black@polyurethane sponge for human-machine interfacing," Advanced Functional Materials, vol. 26, no. 34, pp. 6246-6256, 2016.

[45] L. Pan, A. Chortos, G. Yu et al., "An ultra-sensitive resistive pressure sensor based on hollow-sphere microstructure induced elasticity in conducting polymer film," Nature Communications, vol. 5, no. 1, p. 3002, 2014.

[46] C. L. Choong, M. B. Shim, B. S. Lee et al., "Highly stretchable resistive pressure sensors using a conductive elastomeric composite on a micropyramid array," Advanced Materials, vol. 26, no. 21, pp. 3451-3458, 2014.

[47] Y. Wang, S. Ali, J. Wijekoon, R. H. Gong, and A. Fernando, “A wearable piezo-resistive sensor for capturing cardiorespiratory signals," Sensors and Actuators A: Physical, vol. 282, pp. 215229, 2018.

[48] J. Park, Y. Lee, J. Hong et al., "Giant tunneling piezoresistance of composite elastomers with interlocked microdome arrays for ultrasensitive and multimodal electronic skins," ACS Nano, vol. 8, no. 5, pp. 4689-4697, 2014.

[49] K.-H. Kim, S. K. Hong, N.-S. Jang, S.-H. Ha, H. W. Lee, and J.M. Kim, "Wearable resistive pressure sensor based on highly flexible carbon composite conductors with irregular surface morphology," ACS Applied Materials \& Interfaces, vol. 9, no. 20, pp. 17499-17507, 2017. 


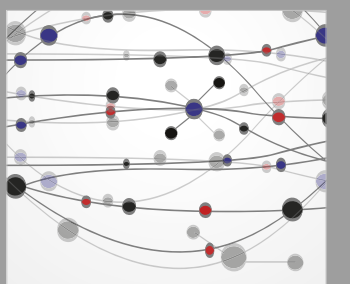

The Scientific World Journal
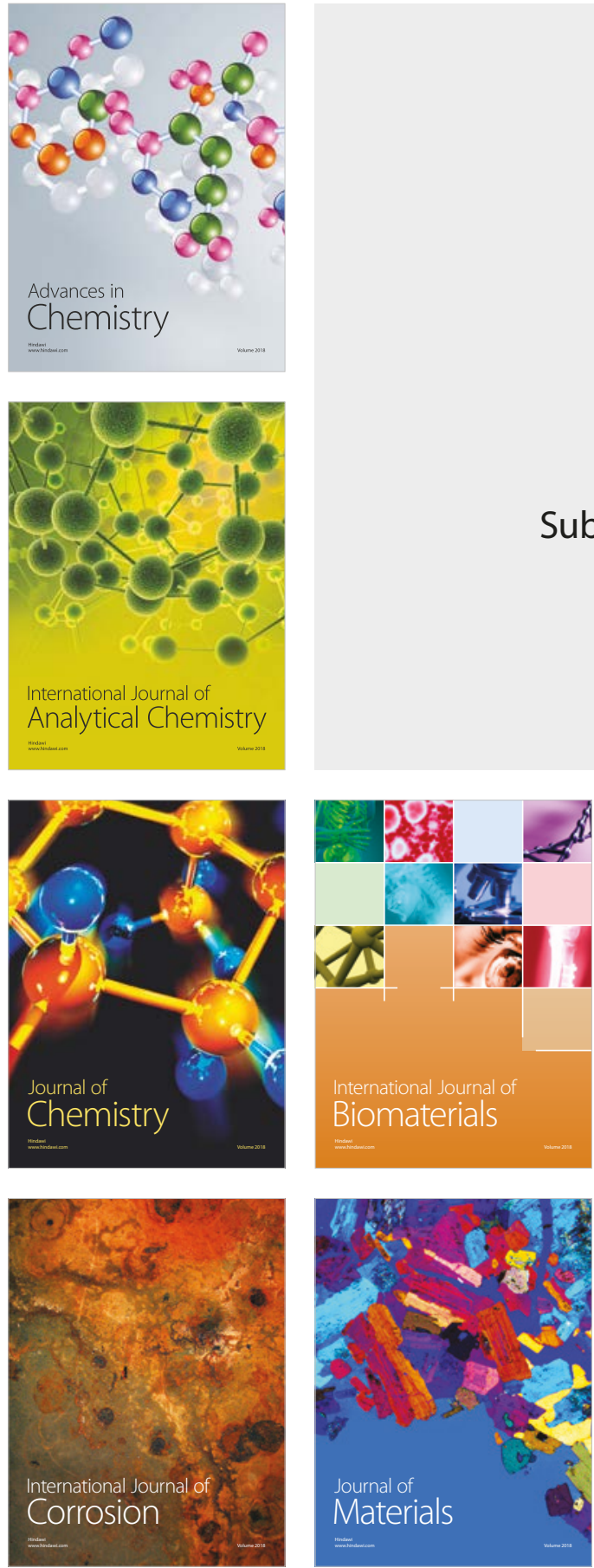

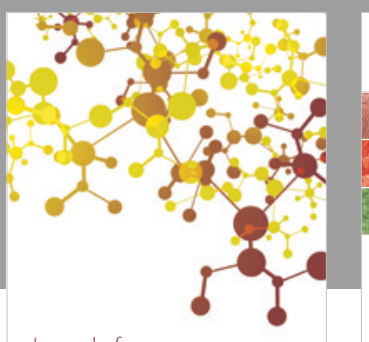

Journal of

Applied Chemistry
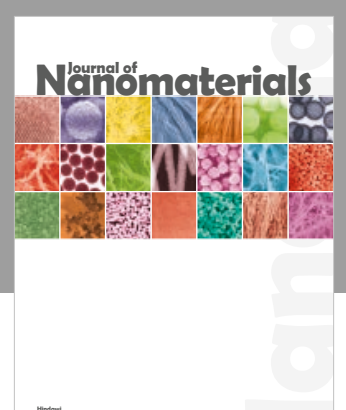

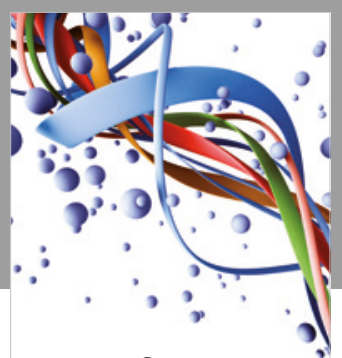

Scientifica

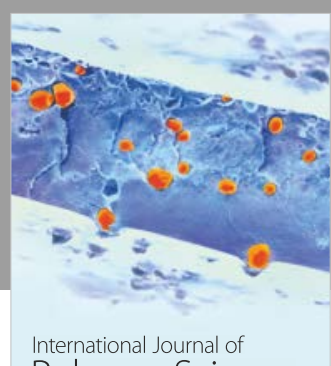

Polymer Science

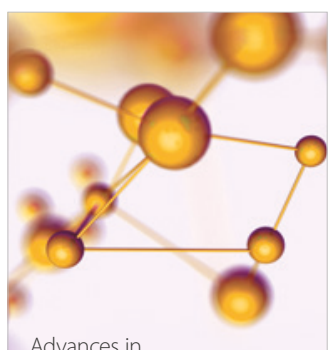

Physical Chemistry
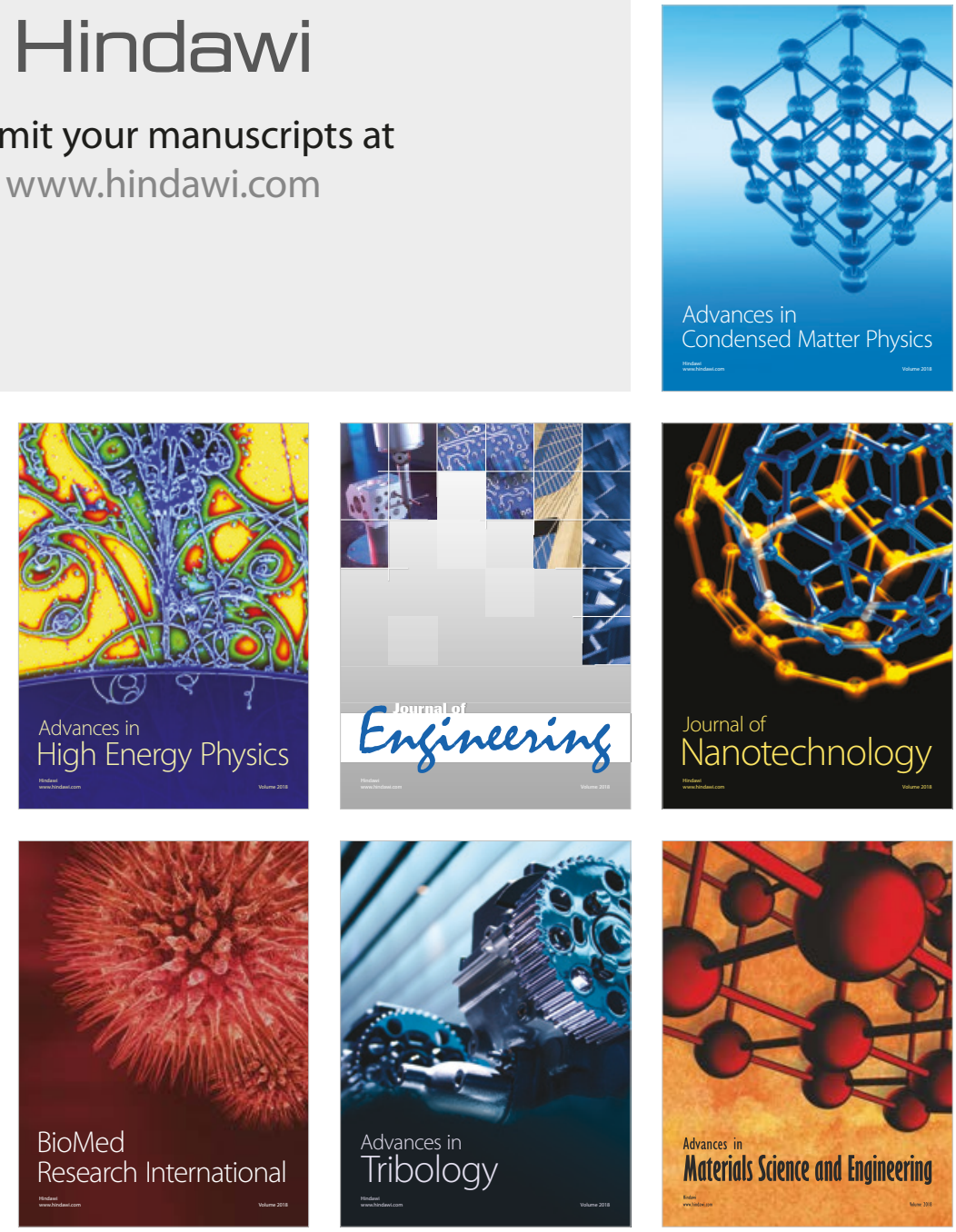